\section{OPEN ACCESS}

Edited by:

Gary Tse,

The Chinese University of Hong Kong, Hong Kong

Reviewed by:

Martin Stiles,

University of Auckland, New Zealand

Henggui Zhang,

University of Manchester,

United Kingdom

*Correspondence:

Ghassen Cheniti

ghassen.chniti@gmail.com

Specialty section:

This article was submitted to

Computational Physiology and

Medicine,

a section of the journal

Frontiers in Physiology

Received: 30 April 2018 Accepted: 26 September 2018

Published: 17 October 2018

Citation:

Cheniti G, Vlachos K, Pambrun T, Hooks D, Frontera A, Takigawa M,

Bourier F, Kitamura T, Lam A, Martin C, Dumas-Pommier C, Puyo S,

Pillois $X$, Duchateau J, Klotz N,

Denis A, Derval N, Jais $P$, Cochet $H$,

Hocini $M$, Haissaguerre $M$ and

Sacher F (2018) Atrial Fibrillation

Mechanisms and Implications for

Catheter Ablation.

Front. Physiol. 9:1458.

doi: 10.3389/fphys.2018.01458

\title{
Atrial Fibrillation Mechanisms and Implications for Catheter Ablation
}

\begin{abstract}
Ghassen Cheniti ${ }^{1,2,3 *}$, Konstantinos Vlachos ${ }^{1,2}$, Thomas Pambrun ${ }^{1,2}$, Darren Hooks ${ }^{4}$, Antonio Frontera ${ }^{1,2}$, Masateru Takigawa ${ }^{1,2}$, Felix Bourier ${ }^{1,2}$, Takeshi Kitamura ${ }^{1,2}$, Anna Lam ${ }^{1,2}$, Claire Martin 1,2, Carole Dumas-Pommier ${ }^{1}$, Stephane Puyo ${ }^{2}$, Xavier Pillois ${ }^{1}$, Josselin Duchateau ${ }^{1,2}$, Nicolas Klotz ${ }^{1,2}$, Arnaud Denis ${ }^{1,2}$, Nicolas Derval ${ }^{1,2}$, Pierre Jais ${ }^{1,2}$, Hubert Cochet ${ }^{2,5}$, Meleze Hocini ${ }^{1,2}$, Michel Haissaguerre ${ }^{1,2}$ and Frederic Sacher ${ }^{1,2}$

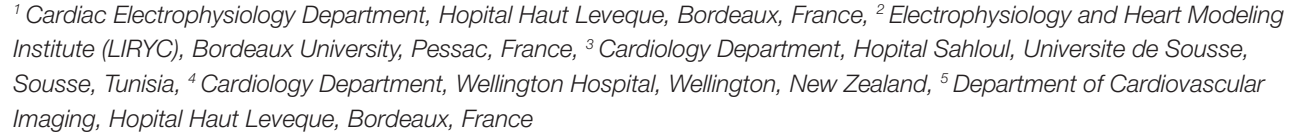
Institute (LIRYC), Bordeaux University, Pessac, France, ${ }^{3}$ Cardiology Department, Hopital Sahloul, Universite de Sousse, Sousse, Tunisia, ${ }^{4}$ Cardiology Department, Wellington Hospital, Wellington, New Zealand, ${ }^{5}$ Department of Cardiovascular Imaging, Hopital Haut Leveque, Bordeaux, France

$\mathrm{AF}$ is a heterogeneous rhythm disorder that is related to a wide spectrum of etiologies and has broad clinical presentations. Mechanisms underlying AF are complex and remain incompletely understood despite extensive research. They associate interactions between triggers, substrate and modulators including ionic and anatomic remodeling, genetic predisposition and neuro-humoral contributors. The pulmonary veins play a key role in the pathogenesis of $\mathrm{AF}$ and their isolation is associated to high rates of $\mathrm{AF}$ freedom in patients with paroxysmal AF. However, ablation of persistent AF remains less effective, mainly limited by the difficulty to identify the sources sustaining AF. Many theories were advanced to explain the perpetuation of this form of AF, ranging from a single localized focal and reentrant source to diffuse bi-atrial multiple wavelets. Translating these mechanisms to the clinical practice remains challenging and limited by the spatio-temporal resolution of the mapping techniques. AF is driven by focal or reentrant activities that are initially clustered in a relatively limited atrial surface then disseminate everywhere in both atria. Evidence for structural remodeling, mainly represented by atrial fibrosis suggests that reentrant activities using anatomical substrate are the key mechanism sustaining AF. These reentries can be endocardial, epicardial, and intramural which makes them less accessible for mapping and for ablation. Subsequently, early interventions before irreversible remodeling are of major importance. Circumferential pulmonary vein isolation remains the cornerstone of the treatment of $A F$, regardless of the AF form and of the AF duration. No ablation strategy consistently demonstrated superiority to pulmonary vein isolation in preventing long term recurrences of atrial arrhythmias. Further research that allows accurate identification of the mechanisms underlying AF and efficient ablation should improve the results of PSAF ablation.

Keywords: atrial fibrillation, reentrant drivers, catheter ablation, fibrosis, mapping, pulmonary vein ablation 


\section{INTRODUCTION}

Atrial fibrillation (AF) is the most common cardiac arrhythmia. It represents a major cause of mortality and morbidity, mainly related to embolic events and heart failure (Benjamin et al., 1998; Ruigomez et al., 2002, 2009; Pedersen et al., 2006; Miyasaka et al., 2007; Potpara et al., 2013; Pandey et al., 2017; Eggimann et al., 2018; Reddy et al., 2018). AF is a heterogeneous rhythm disorder that is related to a wide spectrum of etiologies and has broad clinical presentations. Despite extensive research, the mechanisms underlying AF remain incompletely understood. AF results from interactions between triggers, responsible for its initiation, and the substrate responsible for its perpetuation. In addition, ionic and anatomic remodeling, genetic predisposition, and neuro-humoral contributors make these interactions more complex.

The pulmonary veins play a key role in the pathogenesis of $\mathrm{AF}$ and their isolation is associated to high rates of AF freedom in patients with paroxysmal AF (PAF). However, ablation of persistent AF (PsAF) remains less effective, mainly limited by the difficulty to identify the sources sustaining AF outside the pulmonary veins.

We aimed to review the mechanisms underlying AF and their implications for catheter ablation.

\section{AF PATHOPHYSIOLOGY}

The mechanisms underlying AF are classically described as mechanisms responsible for its initiation (triggers) and mechanisms responsible for its perpetuation (Figure 1). This classification is clinically relevant as it allows to identify therapeutic targets.

\section{AF Triggers}

Haiissaguerre et al. (1998) first reported the essential role of the pulmonary veins (PVs) in the initiation and maintenance of paroxysmal AF (PAF). Ectopic activities originating from the PVs were identified in $94 \%$ of patients suffering from frequent pre-procedural AF episodes. Discrete ablation targeting the site of origin of the ectopic activities abolished the arrhythmia and prevented its recurrence in $62 \%$ of the cases after a follow-up of 8 months. The role of the PVs in triggering AF was confirmed in multiple subsequent studies (Chen et al., 1999; Wu et al., 2001; Sanders et al., 2002; Mahida et al., 2015).

Compared to the atrial cells, the PVs cardiomyocytes have specific action potential properties that predispose to arrhythmogenesis. In fact, the PVs cells have a higher resting membrane potential, a lower amplitude of the action potential, a smaller maximum phase 0 upstroke velocity and a shorter action potential duration (APD). Slow and rapid delayed rectifier currents are greater in the PVs whereas transient outward $\mathrm{K}+$ current and L-type Ca2+ current are smaller (Ehrlich et al., 2003).

The initial premature beats arising from the PVs are focal (Arentz et al., 2007). These beats are likely automatic or triggered and related to calcium handling abnormalities and subsequent delayed afterdepolarizations (DAD) (Hirose and Laurita, 2007;
Takahara et al., 2011; Heijman et al., 2014). They are modulated by acute stressors like atrial stretch (Kalifa et al., 2003) and neural activation (Patterson et al., 2005; Lu et al., 2009). Early after depolarization due to prolonged action potential duration are mainly described in models of long QT syndrome (Lemoine et al., 2011). Subsequent firing is either related to DAD due to abnormal diastolic spontaneous calcium release (Chou et al., 2005; Nattel and Dobrev, 2016) or to reentrant activity at the junction between the PVs and left atrium. In fact, atrial myocytes at the entrance of the PV have abrupt changes in their fiber orientation, leading to slow conduction and reentry (Hocini et al., 2002). In addition, ionic mechanisms facilitate the occurrence of reentry by shortening the APD (increased rapid $\left[\mathrm{I}_{\mathrm{Kr}}\right]$ and slow $\left[\mathrm{I}_{\mathrm{Ks}}\right]$ delayed rectifier $\mathrm{K}+$ currents) and slowing the conduction via the inactivation of $\mathrm{Na}+$ currents (Nattel and Dobrev, 2016).

Additional ectopic sources triggering AF were identified outside the PVs. They can be located in the vena cavae, the crista terminalis, the coronary sinus, the ligament of Marshall, the interatrial septum, the appendages... (Mansour et al., 2002; Lin et al., 2003; Shah et al., 2003; Lee et al., 2005; Yamada et al., 2006; Pastor et al., 2007; Hwang and Chen, 2009; Yamaguchi et al., 2010; Elayi et al., 2013; Enriquez et al., 2017). Lin et al. (2003) identified nonPV triggers in $20 \%$ of the ectopic beats initiating PAF. Non PV triggers were predicted by female gender (odds ratio 2.00, 95\% confidence interval 1.02-3.92) and left atrial enlargement (odds ratio $2.34,95 \%$ confidence interval $1.27-4.32$ ) in patients with PAF (Lee et al., 2005) and are more prevalent in AF of longer duration (Hung et al., 2017). Mechanisms underlying extra-PV triggers are less well-elucidated.

\section{Perpetuation of AF}

Mechanisms underlying the perpetuation of AF are still debated. Multiple wavelets and localized (focal or reentrant) sources are largely accepted to drive AF. These mechanisms are summarized in Figure 2.

\section{Multiple Wavelets Hypothesis}

Multiple wavelets were suggested to perpetuate AF in a mathematical model performed by Moe et al. (1964). In this model, multiple waves randomly propagate through the atria, cause wavebreaks, and give birth to new "daughter" wavelets. Theoretically, the number and the stability of these wavelets prevent AF termination. AF would be sustained as long as the number of wavelets exceeds a critical level. The presence of independent wavelets has been demonstrated in more recent studies (Chen et al., 2000; Reumann et al., 2007; De Groot et al., 2016). However, an important question is whether these wavelets are driving $\mathrm{AF}$ or they are just passive and result from the breakup of more organized waves remains unanswered. Chen et al. (2000) analyzed the individual wavelets during sustained AF by identifying the phase singularities using optical mapping. In their models, the wavelets existed for less than one rotation in $98 \%$ of the cases. In addition, the number of wavelets decreased between the entrance and the exit of the mapping field. These results suggested that wavelets essentially result from the breakup of high frequency organized waves and as such they are not an independent mechanism that maintains of AF. Recording 


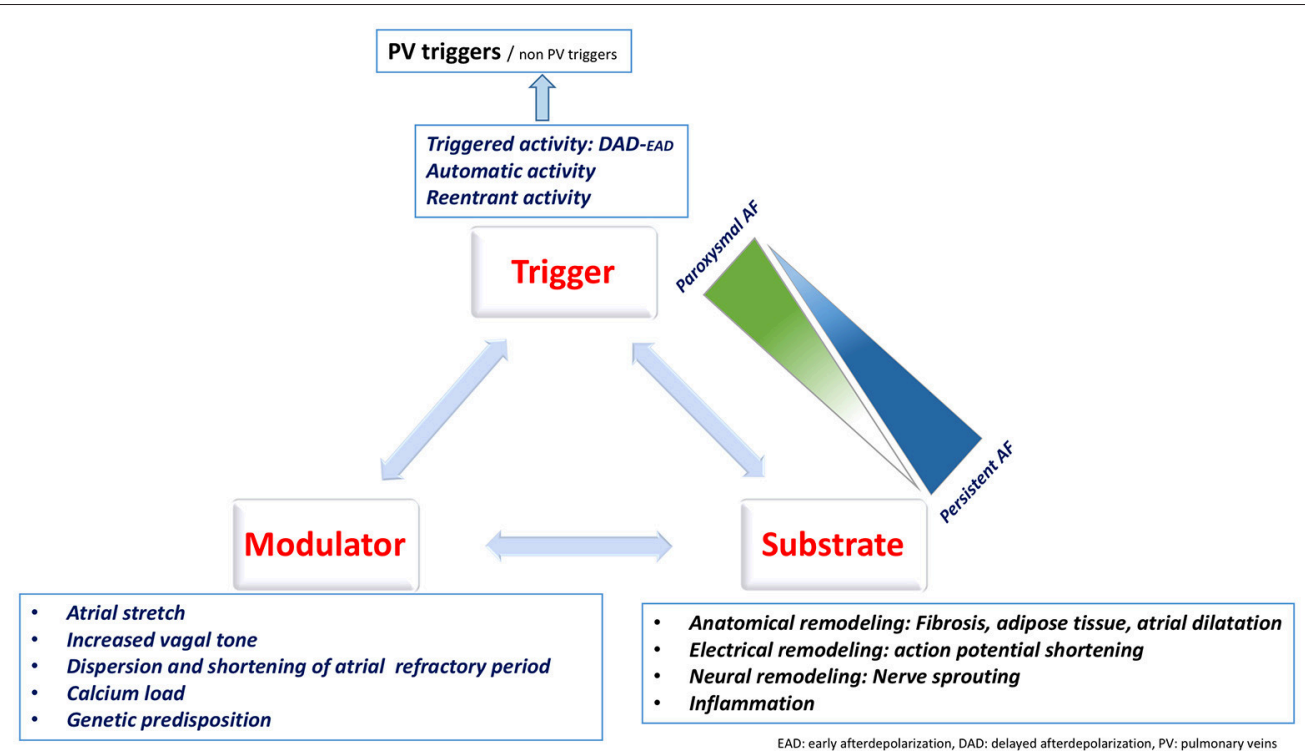

FIGURE 1 | Coumel triangle summarizing the different contributors to AF.

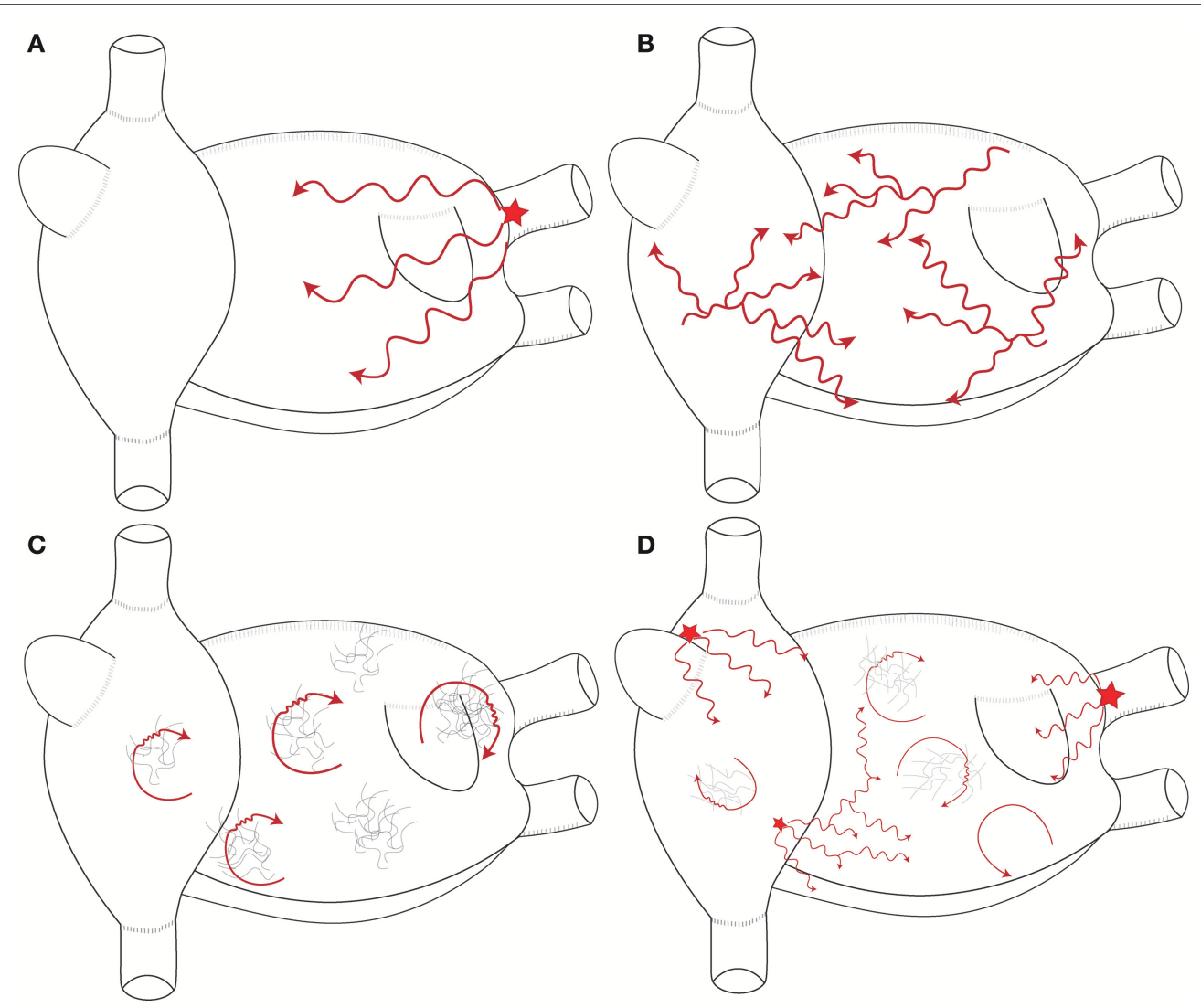

FIGURE 2 | Schematic representation of the mechanisms maintaining AF. (A) Single stable focal or reentrant source (star) with fibrillatory conduction. (B) Multiple wavelets: multiple waves propagate randomly and give birth to new daughter wavelets. (C) Multiple reentries (red arrows) around areas of scar and fibrosis. (D) Combination of the different mechanisms that sustain AF in humans. These mechanisms are typically meandering and last for few consecutive beats. 
multiple wavelets during firing from the PVs is an example that supports the passive role these wavelets.

\section{Localized AF Drivers: (Figure 3)}

There is no specific definition of AF drivers. Hansen et al. (2016) defined AF drivers as localized sources of fast, repetitive activity from which activation propagates and breaks down into fibrillatory conduction in the rest of the atria. This definition refers to localized activities without specifying the underlying mechanism. The driving role of these activities is demonstrated by ablation slowing or terminating AF.

\section{Functional reentry}

Functional reentry refers to reentrant activity in the absence of underlying substrate and of anatomical obstacles.

The leading circle concept: This concept was developed by Allessie et al. (1977). In this theory, centripetal waves moving toward the center maintain this latter refractory. A functional reentry establishes itself in the shortest circuit defined as the shortest distance the impulse travels during the refractory period. The presence of slow conduction velocity $(\mathrm{CV})$ or brief refractoriness (RP) produces a small wavelength $(\mathrm{WL})$ and makes spontaneous termination of $\mathrm{AF}$ unlikely. In fact, as $\mathrm{WL}=\mathrm{CV}$ * $\mathrm{RP}$, the occurrence of a steady state where the WL is adapted to the circuit length would stabilize the reentry and would perpetuate AF.

Spiral wave reentry= rotor concept: Spiral wave reentry or "rotor" is a region of specific reentry where the curved wavefront and wavetail meet each other at a singularity, and where the central tissue is not refractory (Vaquero et al., 2008; Pandit and Jalife, 2013; Nattel et al., 2017).

Evidence for spiral wave reentry was first demonstrated in simulation studies (Winfree, 1973; Goldbeter, 1975; Lechleiter et al., 1991; Pertsov et al., 1993a). Its presence in cardiac tissue was demonstrated using optical mapping by Davidenko et al. (1990). The authors induced sustained reentrant activity by using a single appropriately timed premature electrical stimulus applied perpendicularly to the wake of a propagating quasiplanar wavefront. Reentry pivots at high frequency $(5-7 \mathrm{~Hz})$ around a relatively small group of cells that show only minimal depolarizations (phaseless region) throughout the cycle.

Mandapati et al. (2000) identified micro-reentrant sources localized in $80 \%$ of the cases at the posterior LA, close to the left veins. The authors identified high frequency periodic activity limited to small area $(10.4 \pm 2.8 \mathrm{~mm}$ of core perimeter and $3.8 \pm$ $2.8 \mathrm{~mm}^{2}$ area). Using high resolution video imaging, the localized sources correspond to vortex like reentry.

Spatio-temporal characterization of the rotor activities was facilitated thanks to phase transformation. Gray et al. (1998) analyzed phase singularities during fibrillation and demonstrated a spatial and temporal organization that under certain conditions give rise to rotors. Phase represents the different stages within 1 cycle of a signal divided into $360^{\circ}$ or $2 \pi$ radians (Umapathy et al., 2010).

Phase analysis characterization of the recorded signals lacks temporal accuracy, Bray and Wikswo (2002) developed an algorithm capable of establishing proper orbits without the need to specify "Tau." Using the Hilbert transform, phase singularities could be localized closer to the point of initial formation than was possible previously. This transformation is important for the purposes of singularity tracking and investigating electrodynamic interactions. Phase transformation allows to identify the center of the pivoting rotor as an area of undefined phase and is called phase singularity. This center is surrounded by phases ranging between $-\pi$ and $+\pi$ (Figure 5).

\section{Anatomical reentry}

Localized reentries play a key role in the maintenance of AF. Reentry occurs in the presence of unidirectional block and of slow conduction that makes the wavelength shorter than the length of the circuit. Such conditions are commonly encountered in the atria of patients with AF, mainly in the presence of fibrosis.

The role of reentry in maintaining AF was demonstrated by Schuessler et al. (1992). In their model, the authors induced AF using a single extra-stimulus and increasing concentrations of acetylcholine and mapped the right atrial activation. They noted an increase in the number of wavelets that tended to stabilize to small, single, relatively stable reentrant circuit in the absence of anatomical barriers. These reentries are facilitated by the occurrence of lines of functional block at the crista terminalis.

Spach et al. (1988) showed micro-anatomic reentry (within 1-2 $\mathrm{mm}$ area) that occur in the presence of non-uniform anisotropic conduction and micro-fibrosis of the pectinate bundles of the right atrium (Spach and Dolber, 1986). Hansen et al. (2015) provided the evidence for intramural reentries that anchor to fibrosis insulated atrial bundles. The authors induced AF in explanted Human hearts and mapped intramural activation of the right atrial wall using high resolution optical mapping. They noted stable reentries that anchor to areas with complex architecture marked by increased transmural fiber angle differences and interstitial fibrosis. The majority of the reentries were mapped from the endocardial surface and discrete ablation terminated AF which confirms their driving role. These microreentries were also identified in the left atrium (Zhao et al., 2015) at the junction between the left atrial roof and the posterior wall of the left atrium, at an area with abrupt changes in the myocardial fiber orientation. Ablation of the driver maintain AF can unmask drivers with longer cycle length (Hansen et al., 2015). The presence of several temporally competing drivers and secondary drivers may underlie the absence of acute termination by ablation and should motivate repeated mapping of AF.

AF drivers are more frequently recorded in the left atrium. This is attested by shorter AF CL in the left atrium with a gradient LA-RA, the higher rate of AF termination in the LA. Mansour et al. (2001) analyzed left atrial and right atrial dominant frequencies and identified left to right activation gradient that increased after the ablation of the Bachmann bundle and of the inferoposterior interatrial pathway. This observation supports the higher prevalence of AF drivers in the left atrium with fibrillatory conduction to the right atrium. Hocini et al. (2010) tracked the evolution of AF cycle length at the right and atrial appendages. In $70 \%$ of the cases, an increase of both cycle lengths occurred after left atrial ablation. Right atrial drivers were recorded in $20 \%$ of the cases. 


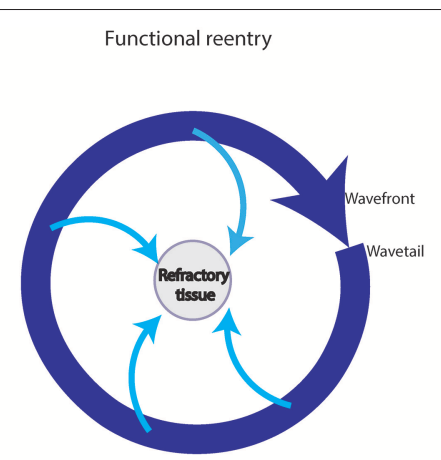

1- Length of circuit determined by conduction velocity and refractory period

2- Length of the circuit can change wih alterations in the electrophysiological properties

3- No gap of full excitabilty (at the smallest circuit)

4-Shortcut of the circuit possible

5- Revolution time proportiional to refractory period

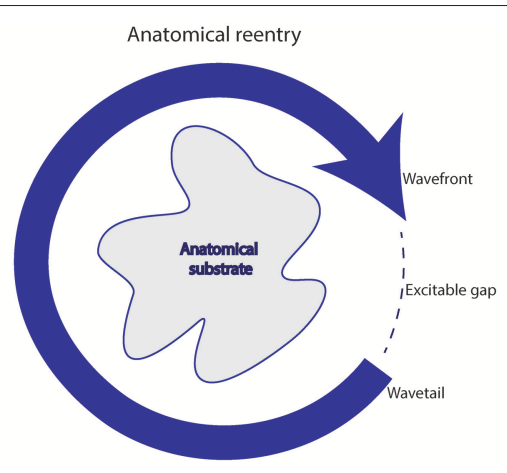

1-Length of the circular pathway determined by the perimeter of the anatomic obstacle 2- Length of the circular pathway fixed 3- Excitable gap between wavefront and the wavetail (dashed line)

4- Impulse can not shortcut the circuit

5- Revolution time inversely related to the conduction velocity

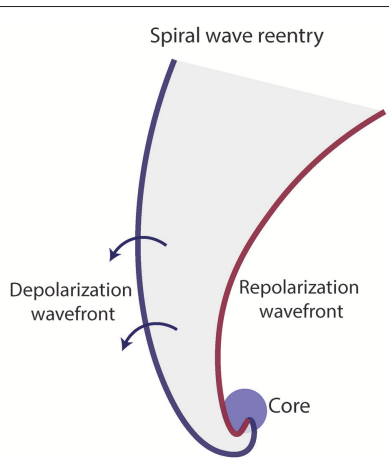

1-The point at which the depolarization and the repolarization curves meet has an undefined voltage state and is usually referred to as the phase singularity point.

2-Curvature of the depolarizing wavefront modulates the propagation velocity

3-Wave-tip trajectories can be circular or meandering

FIGURE 3 | Different reentrant activities maintaining AF (adapted from reference Allessie et al., 1977).

A Paroxysmal AF
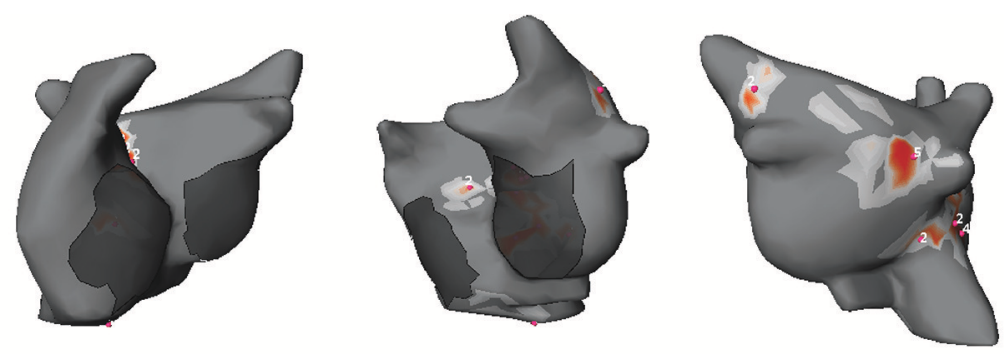

B Persistant AF 4 months
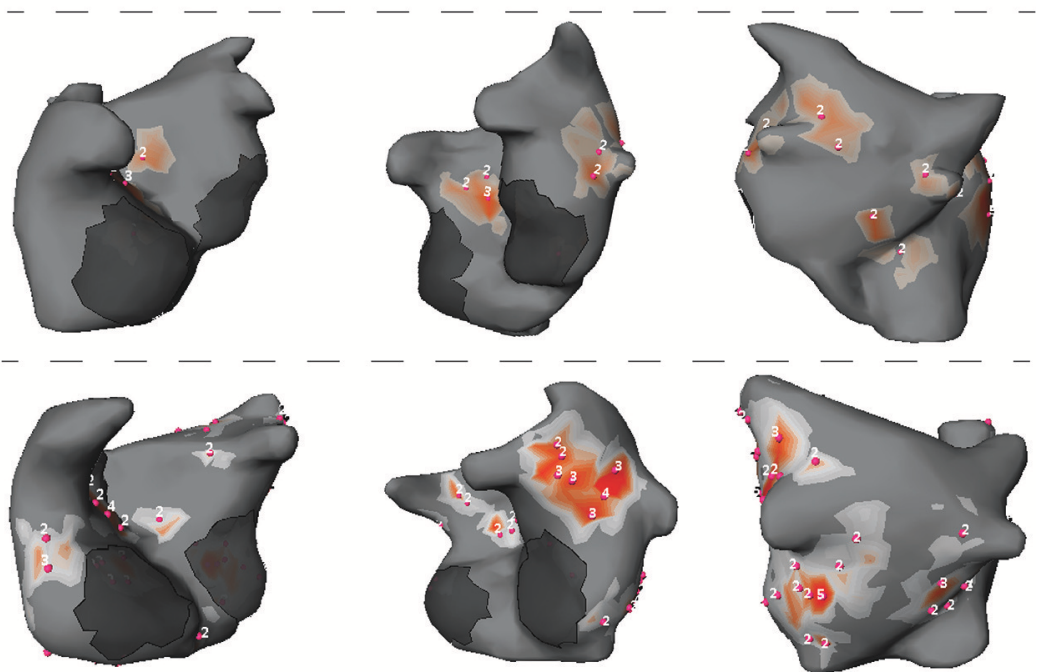

FIGURE 4 | Phase maps acquired during AF in patients with PAF (A), PsAF of 4 months (B) and long lasting PsAF >12 months (C). Red spots identify sites of phase singularity.

\section{Atrial Remodeling}

Atrial remodeling includes structural and functional alterations including electric, structural, and autonomic remodeling that promote atrial arrhythmias.

\section{Electrical remodeling}

$\mathrm{AF}$ and rapid arrhythmias alter the expression and/or the function of ion channels in a way that promotes arrhythmias (Allessie et al., 2002; Schotten et al., 2011; Wakili et al., 2011; 


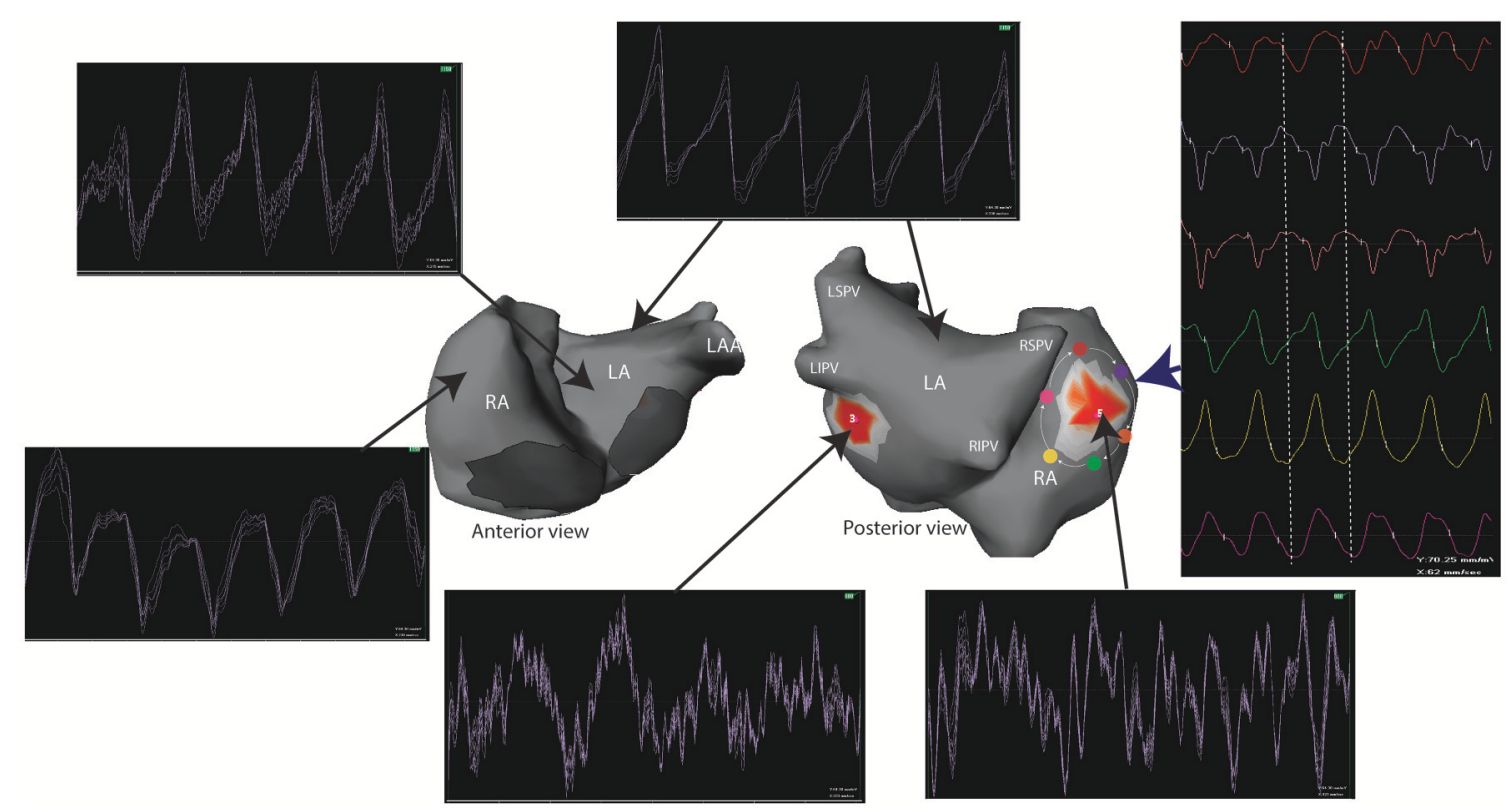

FIGURE 5 | Unipolar signals recorded during a one second window of AF. Electrograms at the site of reentrant activities (red spots) show a complex and turbulent activity while the activity in the remaining atria is homogeneous. A reentry can be identified by analyzing the surrounding electrograms (white arrows) that show a sequential temporal activation. LA, left atrium; LAA, left atrial appendage; LIPV, left inferior pulmonary vein; LSPV, left superior pulmonary vein; RA, right atrium; RIPV, right inferior pulmonary vein; RSPV, right superior pulmonary vein.

Heijman et al., 2014; Nattel and Harada, 2014). In fact, rapid atrial rate during AF initiates auto-protective mechanisms to reduce the entry of $\mathrm{Ca}^{2+}$ inside the cell (Iwasaki et al., 2011). These mechanisms aim to inactivate the $\mathrm{Ca}^{2+}$ currents, downregulate $\mathrm{I}_{\mathrm{CaL}}$, and enhance the inward rectifier $\mathrm{K}^{+}$current. Subsequently, the action potential duration becomes shorter which increases the atrial vulnerability to atrial arrhythmias and stabilizes the mechanisms sustaining AF (Figure 5) (Allessie et al., 2002; Nattel, 2002; Schotten et al., 2011; Wakili et al., 2011). In addition, impaired calcium handling leads to contractile dysfunction and subsequent tachycardia-induced atrial cardiomyopathy (Sun et al., 1998).

\section{Structural remodeling}

Fibrosis represents the most important structural remodeling that promotes $\mathrm{AF}$.

Fibrosis can be reactive (located at the interstitial space) or reparative (replaces dead myocytes) (Silver et al., 1990; Burstein and Nattel, 2008).

Animal studies identified atrial fibrosis in the presence of hypertension (Kistler et al., 2006; Lau et al., 2010a,b, 2013), heart failure (Li et al., 1999; Shi et al., 2002; Shinagawa et al., 2002; Lau et al., 2011), diabetes (Linz et al., 2016), obesity (Abed et al., 2013),... In humans, AF is more frequent in the presence of external stressors predisposing to fibrosis (Sanders et al., 2003; John et al., 2008; Roberts-Thomson et al., 2009; Medi et al., 2011, 2012; Dimitri et al., 2012; Vlachos et al., 2016; Anter et al., 2017; Karam et al., 2017). In addition, when left untreated, AF promotes the expression of genes that enhance the proliferation of fibroblasts and increase extra-cellular matrix secreting function (Burstein et al., 2007; Guo et al., 2012). This underlies the progression of AF to permanent forms by creating a long-term positive feedback loop (Platonov et al., 2011; Yue et al., 2011); the so called AF begets AF hypothesis (Wijffels et al., 1995; Rostock et al., 2008).

Fibrosis increases the separation of the myocytes within subendocardial atrial bundles and between the endocardial and epicardial layers leading to endo-epicardial dissociation (Spach and Dolber, 1986; Verheule et al., 2013; Hansen et al., 2017). It forms barriers to the propagation of the activation wavefronts and isolates atrial myocytes. These obstacles affect the wavefront shape and can induce spiral waves through vortex shedding or by causing localized conduction block in narrow isthmuses (Panfilov and Keener, 1993; Cabo et al., 1996; Starobin et al., 1996). The interaction between the wavefront and the boundaries of the fibrotic area are determinant for the wavefront curvature by influencing the propagation velocities and the refractory periods (Comtois and Vinet, 1999; Sampson and Henriquez, 2002). This stabilizes rotor activity (Morgan et al., 2016; Roney et al., 2016) and anchors them to the scar boundaries (Davidenko et al., 1992; Pertsov et al., 1993b; Morgan et al., 2016).

In addition, the fibrotic pattern affects the velocity of the activation wavefront (Kawara et al., 2001; Comtois and Nattel, 2011). In a mathematical model, Tusscher and Panfilov (2005) demonstrated that an increasing number of small and randomly distributed obstacles decrease the conduction velocity but increase the inducibility of wavebreaks and spiral waves in 2D and 3D excitable media. Kawara et al. (2001) analyzed the wavefront activation in explanted human hearts and identified different conduction curves according to the 
fibrotic pattern. The zones of dense, patchy fibrosis with long fibrotic strands were associated with prominent activation delay. The conduction curve in this situation was dependent on the fiber direction. Conversely, dense, diffuse fibrosis with short fibrotic strands only marginally affected conduction curves.

In a recent study, Vigmond et al. (2016) demonstrated the possibility to induce percolation in a computer model of fibrotic tissue. Percolation was produced as a result of micro-source-sink mismatch with the fibrotic region. This produced low amplitude and long lasting electrograms. Decreasing the cycle length increased the delay needed for the wavefront to exit the remodeled zones and induced reentrant activities. Additional studies demonstrated the occurrence of reentry near the percolation threshold in heterogeneous cardiac tissue including fibrosis (Alonso and Bar, 2013; Alonso et al., 2016).

In addition to fibrosis, structural atrial remodeling includes atrial fatty infiltration, inflammatory infiltration, necrosis and amyloid deposition (Frustaci et al., 1997; Rocken et al., 2002; Leone et al., 2004; Nguyen et al., 2009; Hatem and Sanders, 2014; Venteclef et al., 2015). The role of the adipose tissue in the pathogenesis of AF is well-demonstrated. Adipose tissue has a paracrine effect through the release of adipokines with profibrotic properties. It also forms barriers to wavefront conduction and favor reentrant circuits (Hatem and Sanders, 2014).

\section{Autonomic and neural remodeling}

The heart has a rich and complex extrinsic and intrinsic autonomic innervation (Janes et al., 1986; Armour et al., 1997; Armour, 2008). The role of this system in the initiation and maintenance of AF is well-demonstrated (Arora, 2012; Chen et al., 2014) and is supported by the circadian variation in the incidence of AF (Viskin et al., 1999; Mitchell et al., 2003).

Neural remodeling including an increase in the atrial innervation occurs in different clinical situations. Animal studies (Jayachandran et al., 2000; Chang et al., 2001; Arora et al., 2008; $\mathrm{Ng}$ et al., 2011) demonstrated an increase in the density of sympathetic and parasympathetic innervation with AF. Gould et al. (2006) collected the atrial appendages in patients with AF undergoing cardiac surgery and demonstrated an increased atrial sympathetic innervation in patients with PsAF.

Neural remodeling also occurs after myocardial infarction (Han et al., 2012; Nguyen et al., 2012; Ajijola et al., 2015) and in the presence of cardiomyopathy (Ajijola et al., 2012) and contributes to the occurrence of AF in these populations. Recent therapeutic strategies aiming to modulate the autonomic tone successfully reduced the AF burden in animal models (Richer et al., 2008; Ogawa et al., 2009; Leiria et al., 2011; Shen et al., 2011) and in humans (Pappone et al., 2004; Scanavacca et al., 2006; Po et al., 2009; Katritsis et al., 2013; Pokushalov et al., 2013).

It is important to note that, in contrast with the electrical remodeling, structural remodeling and fibrosis are not reversible and lead to the perpetuation of AF in more complex forms. Early interventions are of major importance to avoid such progression of the disease.

\section{Genetic Predisposition}

Genetic predisposition plays an important role in the occurrence of AF. It is responsible for familial cases with early onset of AF independently of concomitant cardiovascular conditions (Fox et al., 2004; Lubitz et al., 2010; Oyen et al., 2012). AF incidence also shows racial differences, being less prevalent in Blacks, Hispanics and Asians compared to Whites (Dewland et al., 2013).

Up to one-third of the patients with AF had genetic variants that increase the risk of AF. So far, the genome wide association study (GWAS) and international collaborative metanalysis identified at least 30 gene loci associated to AF (Gudbjartsson et al., 2007; Benjamin et al., 2009; Ellinor et al., 2010, 2012; Sinner et al., 2014; Low et al., 2017; Bapat et al., 2018; Campbell and Wehrens, 2018).Variants located close to the paired-like homeodomain 2 (PITX2) gene on chromosome 4q25 have the highest association to AF (Lubitz et al., 2014; Low et al., 2017). The majority of mutations underlying AF affect genes that encode transcription factors related to cardiopulmonary development, cardiac-expressed ion channels and cell signaling molecules (Roberts and Gollob, 2010, 2014; Ellinor et al., 2012). Genome wide association studies have allowed identification of variants potentially linked to AF (Christophersen et al., 2017; Lee et al., 2017; Low et al., 2017; Nielsen et al., 2018a,b; Roselli et al., 2018). These variants frequently require further classification to confirm or eliminate their pathogenicity. Genetic predisposition may influence the response to AF therapies (Darbar et al., 2007; Parvez et al., 2012; Benjamin Shoemaker et al., 2013; Huang and Darbar, 2016) and can allow specific and based-mechanism therapies (Roberts and Gollob, 2010; Campbell et al., 2013; Faggioni et al., 2014; Darbar, 2016).

\section{MAPPING OF AF}

Mapping represents a crucial step to understand the mechanisms of AF and improve the results of ablation. However, it is important to note that the spatial resolution of the mapping technique can significantly affect the interpretation of the underlying AF mechanism (Roney et al., 2017).

\section{Invasive Mapping of Reentrant and Focal Activities}

Narayan et al. (2012b) used a 64 pole-basket catheter $(48 \mathrm{~mm}$ diameter, $4 \mathrm{~mm}$ electrode spacing; or $60 \mathrm{~mm}$ diameter, $5 \mathrm{~mm}$ electrode spacing) introduced through a venous femoral access to map AF activities from the right and the left atria. They included 97 patients who underwent 107 consecutive ablation procedures for PAF or PsAF. AF electrograms at 64-128 electrodes are combined with repolarization dynamics acquired using monophasic action potentials (MAP) and conduction dynamics to construct spatiotemporal AF maps (Narayan et al., 2012a). These maps were used to locate the focal impulses (defined as centrifugal activation contours from an origin) and rotors (defined as sequential clockwise or counterclockwise activation contours around a center of rotation emanating outwards to control local AF activation). Rotors and focal impulses were present in $97 \%$ cases with sustained AF. The majority of the 
AF sources were rotors (70\%) and predominantly located in the left atrium (76\%). In contrast to our experience, no fragmented signals were recorded at the rotors site. The mean AF sources was $2.1 \pm 1.0$ and was significantly higher in PsAF than PAF and in spontaneous than induced AF. A group of patients underwent ablation targeting Focal Impulse and Rotor Modulation (FIRM guided ablation). Compared to patients undergoing conventional AF ablation, FIRM guided ablation was associated to a higher acute success and a better outcome.

Different systems were developed to invasively map rotational activities (Daoud et al., 2017; Grace et al., 2017; Honarbakhsh et al., 2017). The systems use different approaches and more studies are needed to evaluate their clinical usefulness.

\section{Limitations of Invasive Mapping of Reentrant and Focal Activities}

The FIRM approach needs the use of two basket catheters for concomitant bi-atrial analysis. Poor electrode contact and inefficient deployment may significantly alter the recorded signals (Laughner et al., 2016; Oesterlein et al., 2016). In addition, low resolution of mapping the atria may lead to false detections (Roney et al., 2017). Offline analysis is needed which prolongs the duration of the procedure and limits the reproducibility of the results (Benharash et al., 2015; Buch et al., 2016). In addition, there are significant discrepancies between $2 \mathrm{D}$ and $3 \mathrm{D}$ phase maps where rotors identified using 2-D maps were absent in 3D maps (Pathik et al., 2018).

\section{Non-invasive Mapping \\ Principles of Non-invasive Mapping}

Electrocardiographic mapping (ECGi) is a technology that allows to map the activation of AF from chest recordings in a beatto-beat manner (Oster et al., 1997; Ramanathan et al., 2004; Cuculich et al., 2010; Frontera et al., 2018a). This technique is particularly useful to map focal sources and non-sustained arrhythmia (Jia et al., 2006; Wang et al., 2011; Shah et al., 2013; Zhang et al., 2013; Cochet et al., 2014).

Recording of the cardiac activity is acquired from the torso using a 252 electrode vest. The cardiac geometry and the position of each electrode is registered using high-resolution cross sectional non-contrast computed tomography. The ECGi algorithm computes epicardial unipolar electrograms from the input geometry and torso potentials by solving the inverse problem (Gulrajani et al., 1988; Rudy and Messinger-Rapport, 1988; Rudy and Oster, 1992; Ramanathan et al., 2003; Rudy, 2013). To avoid the superposition of the QRS, windows with long R-R interval exceeding one second allow to analyze the fibrillatory waves.

Additional algorithms can be applied to acquire different maps. Activation maps are computed using the unipolar electrogram intrinsic deflection $(\mathrm{dV} / \mathrm{dt})$ based method. Phase analysis identifies reentrant and focal activities. Reentrant activity is identified as a phase singularity formed at the intersection of depolarization and repolarization isolines (Gray et al., 1998). Focal breakthroughs are shown as activities raising from discrete points and showing a negative pattern of the local electrogram.

\section{Results From Non-invasive Mapping}

Cuculich et al. (2010) first used ECGi to map AF in 26 patients. The spatial accuracy for determining different pacing sites was $6 \pm 4 \mathrm{~mm}$. The authors identified multiple wavelets (defined as contiguous area of epicardial activation lasting $\geq 5 \mathrm{~ms}$ ) as the most common pattern ( $92 \%$ of the patients). Rotor activity was present in $15 \%$ of the cases, only in patients with non-paroxysmal AF. The authors defined a complexity index as the sum of the number of wavelets and focal activities and showed an increased complexity with duration of AF.

Data from our laboratory (Haissaguerre et al., 2014; Lim et al., 2017) reported the results of 103 patients with PsAF. The analysis of cumulative windows of $9 \pm 1 \mathrm{~s}$ of AF were performed using phase mapping. AF was driven by two to three regions of reentrant and focal activities during the first months. Drivers activity spread in more regions and became bi-atrial in PsAF of longer duration (Figure 4). Reentrant drivers were located in the PV antra and surrounding structures, the left atrial appendage and septum in nearly all the cases. Focal breakthroughs rose predominantly from the PV ostia and left and right appendages.

In the AFACART study (Knecht et al., 2017), ECGi was used to guide ablation in 118 patients with PsAF lasting $<1$ year. Reentrant activities were identified in all patients and were more frequently located around the PVs, at the anterior interatrial groove and the posterior and inferior left atrium. Focal breakthroughs were mapped in 95\% of the cases and were more commonly located in the PVs and both appendages.

Metzner et al. (2017) used a noninvasive epicardial and endocardial system (NEEES) and compared the epicardial and the endocardial reentrant activity. The authors acquired phase maps from 6 patients with PsAF. The majority of the epicardial rotor activity was located in two to three anatomical clusters. These results were reproduced using invasive mapping by a multipolar catheter.

The effects of antiarrhythmic drugs were analyzed in a group of 13 patients who underwent ablation for PsAF (Amraoui et al., 2016). ECGi recordings were acquired before and after the infusion of flecainide. Flecainide infusion reduced the number of regions that hosted reentrant activity (7-4 regions, $p<0.001$ ). Importantly, AF was terminated to sinus rhythm in 11 cases, by targeting the regions remaining after flecainide infusion in 9/11 cases. This result suggests that anti arrhythmic drugs select more stable and important regions that sustain AF. Similarly, amiodarone was used in patients with structural heart disease and PsAF and allowed to terminate AF using a shorter duration of radiofrequency (Cheniti et al., 2016). In our practice, an antiarrhythmic drug is used before ablation for PsAF order to limit the effects of the electrical remodeling.

\section{Limitations of Non-invasive Mapping}

Non-invasive mapping has some limitations that should be considered for optimal use. Cardiac signals are attenuated while crossing the thorax, leading to a "blurred vision" by the recording electrode on the torso. Subsequently, the recorded signals by each electrode on the torso represents the average of multiple signals. However, areas with turbulent activity can still be distinguished from areas with more organized activity (Figure 5). 
ECGi does not explore intra-mural and endocardial activities. Subsequently, it is unable to discern the mechanisms of focal activities that may be microreentry, epicardial breakthrough of endocardial activity, focal activity (Cuculich et al., 2010). It is also unable to accurately analyze the septal activity where wavefronts from the left and right atria can be projected. In addition, phase transformation can produce phase generated non-rotational singularity points and false rotors (Vijayakumar et al., 2016). In our practice, signals at the reentrant site are manually validated by showing electrograms that cover all the cycle length.

\section{Invasive Mapping of AF}

Invasive mapping is limited by the inability to map simultaneously both atria, by contact issues, by mechanical movement of the atrial walls, by the inability to explore intramural and epicardial activities. The meandering nature of the sources maintaining $\mathrm{AF}$ is an additional major limitation to conventional sequential invasive mapping. Multipolar catheters with small electrodes improved the mapping of AF by acquiring high density maps and reducing the influence of farfield signals.

\section{Findings During Invasive Mapping of AF}

Konings et al. (1994) used a spoon shaped electrode containing 244 unipolar electrodes to map right atrial free wall in patients undergoing surgical ablation of accessory pathways. The authors identified 4 major patterns of activation according to the complexity of the atrial activation. Single broad wavefronts propagating uniformly across the right atrium were recorded in $40 \%$ of the cases. One or two non-uniformly conducting wavelets were recorded in $32 \%$ of the cases. Highly fragmented signals with more than two wavelets and variable direction of propagation were less frequent and recorded in $28 \%$ of the cases. The authors correlated the morphology of the signals recorded to the underlying mechanism (Konings et al., 1997). Unipolar signals were different according to the underlying mechanisms, showing single potentials in uniform conduction, short double potentials in areas of collision, long double potentials in areas with conduction block and fragmented potentials in pivoting points and in the presence of slow conduction. No preferential anatomic sites for double or fragmented potentials were found in the right atrium. The authors hypothesized that electrograms spanning the entire cycle length of the AF could identify localized reentries and areas where electrograms displayed fractionation could be pivotal points of these circuits. Fragmented signals with long duration are referred to as complex fractionated atrial electrograms (CFAE) and represented an important target for AF ablation (Nademanee et al., 2004). Different algorithms were developed in order to automatically locate the areas of CFAEs (Scherr et al., 2007; Verma et al., 2008; Seitz et al., 2013; Namino et al., 2015).

Rostock et al. (2006) performed high density endocardial mapping during AF using a 20-pole catheter. The authors identified two patterns of local activation. In the majority of the cases, they recorded nearly simultaneous activation covering only a limited part of the cycle length ( $\leq 30 \%$ of the AF cycle length). This pattern was correlated to passive activation. More rarely, they recorded complex activation covering more than $75 \%$ of the cycle length. These signals were correlated either to local burst activity with activation gradient in the adjacent splines and may be related to localized reentry.

Haïssaguerre et al. (2006) used a 20-pole catheter with 5 radiating splines covering $3.5-\mathrm{cm}$ diameter to map both atria. The authors identified activity spanning $75-100 \%$ of the cycle length suggesting a complex localized activity or localized reentry. Ablation targeting these areas significantly prolonged the AF cycle length demonstrating the critical role of these reentries in the maintenance of AF. This result is consistent with the findings of Hansen et al. (2016) identified micro-reentrant activity with average area around $15^{*} 6 \mathrm{~mm}$ with $3 \mathrm{~mm}$ depth. As such, these reentries may be mapped using high resolution catheters, but only if they are located on the endocardial or epicardial surface.

High density endocardial mapping at the drivers' area identified prolonged fractionated signals. These signals were more frequent in the driving area than in the remaining areas (62 vs. $40 \%, p<0.001$ ). Most importantly, electrograms recorded on the multispline catheter spanned across a greater part of AF cycle length in the driver regions than elsewhere (71 vs. $47 \%$ of the AF cycle length, $P<0.001$ ) (Haissaguerre et al., 2014). This suggests a slow conduction or a localized reentry. These electrograms were rarely recorded for more than five consecutive beats indicating an unstable local propagation (Haissaguerre et al., 2016). In addition, these signals may show dynamic changes that are dependent on the local cycle length (Rostock et al., 2006). The instability of the electrograms is suggested by the smoothing of the local activity which shows a turbulent activity. In fact, unipolar signals at the site of reentry identified complex and turbulent activity spanning all the cycle length, while activation in the remaining atria are more homogeneous (Figure 5). In our experience, the persistence of complex activity at driver sites after ablation is associated to the persistence of AF and demonstrates the necessity for further ablation.

\section{Limitations of the Mapping of Fragmented Signals}

Multiple parameters may affect the accuracy of invasive mapping. The electrode size, the inter-electrode spacing, the proximity to the atrial wall and the duration of the mapping at each site represent the main parameters. Mapping catheters with small electrodes provide a higher sensitivity to near-field signals compared to $4 \mathrm{~mm}$ tip catheters (Stinnett-Donnelly et al., 2012; Berte et al., 2015). In addition, fractionation increases as interelectrode spacing increases (Correa De Sa et al., 2011; Lau et al., 2015).

The correlation between the fragmented signals and the underlying mechanism is poor. In fact, complex and fragmented signals may result from artifacts, inappropriate filtering, remote activation related to adjacent structure or overlying structures and alterations in conduction velocities related to wavefront curvature and tissue discontinuities (De Bakker and Wittkampf, 2010). In addition, these fragmented signals are frequently passive. Jadidi et al. (2012) acquired high density atrial maps during sinus rhythm, CS pacing and during AF. The distribution of the fragmented electrograms was different according to the site and the rate of activation. During sinus rhythm and 
CS pacing, electrogram fragmentation mainly resulted from wavefront collision.

Recent work from our laboratory characterized the mechanism underlying the different types of electrograms using high density mapping (Rhythmia, Boston Scientific) during atrial tachycardia. Frontera et al. (2018b). analyzed electrograms at the sites of slow conduction areas, at the lines of block, at areas of collision and at pivot sites. Areas with slow conduction had a significantly lower amplitude and a long duration. Areas of wavefront collision had a shorter amplitude and a higher voltage. Electrograms at the lines of block were not fragmented, the block lines being defined as areas where the activation completely stopped with the front making a detour around the obstacle, the downstream activation proceeding toward the line of block being in an opposite direction to the upstream one. These characteristics should be assessed during AF.

\section{Contribution of Imaging Modalities to AF Mapping}

Cardiac magnetic resonance (CMR) studies demonstrated a higher proportion of atrial fibrosis in patients with AF compared to healthy patients (Oakes et al., 2009) and in patients with PsAF compared to those with PAF (Oakes et al., 2009; Daccarett et al., 2011).

Oakes et al. (2009) validated a processing protocol to detect atrial fibrosis by using late gadolinium enhancement (LGE) on CMR. This technique was used to characterize the atrial substrate in a group of 81 patients undergoing PV isolation. Fibrosis was present in all cases and its extent predicted the recurrence of AF after PVI. In the DECAAF study (Marrouche et al., 2014), Marrouche et al. demonstrated that an increase of $1 \%$ in the proportion of atrial fibrosis was associated to $6 \%$ increase in rate of recurrent arrhythmia after catheter ablation. In addition, residual fibrosis on MRI, defined as preablation atrial fibrosis not covered by ablation scar, was associated to the recurrence of AF (Akoum et al., 2015). These studies confirm the key role of fibrosis in the pathogenesis of AF.

Electrograms at the areas with fibrosis were analyzed by Jadidi et al. (2013) in a group of patients undergoing ablation for persistent and long-lasting PsAF. Atrial fibrosis was associated with lower amplitude and a slower and more organized activity. However, complex fractionated atrial electrograms were recorded outside the areas of fibrosis in $90 \%$ of the cases.

Haissaguerre et al. (2016) analyzed the presence of fibrosis and its density within each $2.5 \mathrm{~mm}$ spherical atrial volume in 13 patients undergoing CMR. The borders of the fibrotic areas hosted the majority of the reentrant activities. In fact, $80 \%$ of the reentrant activities were located in areas with a fibrotic density $>70 \%$. Conversely, only $10 \%$ of the non-driver region harbored such a high fibrotic density.

In a recent study, Cochet et al. (2018) used high resolution LGE-CMR to characterize atrial fibrosis in patients with AF undergoing ECGi guided catheter ablation. The authors characterized LGE density at the reentrant sites. Fibrosis was significantly associated with the number of reentrant regions, to the left atrial volume and to the AF duration. Interestingly, reentrant activities were predominantly clustered at the LGE borders. Moreover, areas with high reentrant activity had a significantly higher local LGE density.

Fibrosis identified by CMR was shown to be an independent factor of AF recurrence after catheter ablation. In a post-analysis of the DECAAF study, Akoum et al. (2015) analyzed LGE CMR 3 months after the ablation in 177 cases. Baseline fibrosis and residual fibrosis were significantly correlated to the need for repeat catheter ablation. Similar results were reported in other studies (Oakes et al., 2009; Malcolme-Lawes et al., 2013; Khurram et al., 2016). Interestingly, CMR studies demonstrated a low rate of complete encirclement of the four pulmonary veins, only in around 7\% of the cases (Badger et al., 2010; Akoum et al., 2015). Incomplete PVI is associated to higher recurrence after AF ablation (Peters et al., 2009; Badger et al., 2010). These results raise multiple questions about the efficiency and the durability of lesions caused by ablation.

\section{IMPLICATIONS FOR AF ABLATION}

Clinical AF ablation provides clues about the understanding of AF pathophysiology. In Table 1 are presented the results of the main studies and the outcome after percutaneous AF ablation. Unfortunately, there is a significant heterogeneity between the different studies leading to poor reproducibility of the results.

Catheter ablation is superior to antiarrhythmic drugs in preventing $\mathrm{AF}$ recurrence (Hazard ratio $=0.53$ ) as reported in the CABANA trial. However, the best strategy is still to be identified.

Despite the different techniques, CPVI remains the cornerstone of the treatment of $\mathrm{AF}$, regardless of the $\mathrm{AF}$ form and of the AF duration (Voskoboinik et al., 2017). No strategy consistently demonstrated superiority to CPVI in preventing long term recurrences of atrial arrhythmias.

It is notable that higher rates of success are reported after multiple procedures (Ganesan et al., 2013). This raises questions about the identification of the mechanisms underlying AF and the efficiency and the durability of the lesions created during index procedures.

\section{Paroxysmal AF}

$\mathrm{PV}$ isolation (PVI) is the most widely used technique to treat PAF. The initial strategy targeted the earliest activation site by performing a focal and discrete ablation (Haïssaguerre et al., 1998). However, this technique was associated to high rates of pulmonary vein stenosis (Rostamian et al., 2014). Later, wide area circumferential ablation that disconnects the PV two by two became the strategy of choice. This technique is thought to have better results (Lo et al., 2007) by targeting the trigger sources and the ostial drivers and also by autonomic denervation (Redfearn et al., 2007).

PVI is associated with high rates of freedom from AF recurrence. The freedom rate from AF recurrence varies between 60 and 79\% (Katritsis et al., 2008; Takigawa et al., 2015a; Straube et al., 2016; Kis et al., 2017), 60 and $72 \%$ at 3 years (Vogt et al., 2013; Takigawa et al., 2015a; Takarada et al., 2017) and decreases 
TABLE 1 | Summary of the different approaches of percutaneous ablation of AF.

\begin{tabular}{|c|c|c|c|c|}
\hline References & Population & Ablation technique & Acute results/main findings & Long term outcome \\
\hline \multicolumn{5}{|l|}{ PVI } \\
\hline Haïssaguerre et al., 1998 & 45 PAF & $\begin{array}{l}\text { Earliest site of activation of the } \\
\text { ectopic beat initiating AF }\end{array}$ & $\begin{array}{l}69 \text { ectopic sites, } 94 \% \text { originating from } \\
\text { the PV }\end{array}$ & $62 \%$ AF freedom after $8 \pm 6$ months \\
\hline Chen et al., 1999 & 79 PAF & $\begin{array}{l}\text { Earliest site of activation of the } \\
\text { ectopic beat initiating AF }\end{array}$ & $\begin{array}{l}116 \text { ectopic foci, } 88.8 \% \text { originating } \\
\text { from the PV }\end{array}$ & $\begin{array}{l}86 \% \text { AF freedom after } 6 \pm 2 \text { months, } \\
\text { Focal stenosis in } 42.4 \% \text { of the PVs }\end{array}$ \\
\hline Haissaguerre et al., 2000 & 70 PAF & $\begin{array}{l}\text { PV isolation (except RIPV) by } \\
\text { targeting atrial breakthroughs }\end{array}$ & & $\begin{array}{l}73 \% \text { AF freedom after } 4 \pm 5 \text { months, } \\
\text { ( } 29 \text { patients had re-ablation session) }\end{array}$ \\
\hline Deisenhofer et al., 2003 & $\begin{array}{l}\text { - } 69 \text { PAF } \\
\text { - } 6 \text { PSAF }\end{array}$ & Segmental PVI & $\mathrm{PVI}$ achieved in $89 \%$ of the veins & $\begin{array}{l}51 \% \text { AF freedom after } 230 \pm 133 \\
\text { days } \\
40 \% \text { underwent second procedure: } \\
90 \% \text { due to PV reconnection }+40 \% \\
\text { extra-PV foci }\end{array}$ \\
\hline Arentz et al., 2003 & $\begin{array}{l}\text { - } 37 \text { PAF } \\
\text { - } 18 \text { PsAF }\end{array}$ & Segmental PVI & $\mathrm{PVI}$ achieved in $99 \%$ of the veins & $\begin{array}{l}27 \text { pts underwent a second } \\
\text { procedure } \\
62 \% \text { event free after one-year } \\
\text { follow-up } \\
70 \% \text { for PAF, } 44 \% \text { for PSAF }\end{array}$ \\
\hline $\begin{array}{l}\text { SMART AF } \\
\text { Natale et al., } 2014\end{array}$ & • 172 PAF & $\begin{array}{l}\text { - } 160 \text { PVI using contact force } \\
\text { sensing catheter } \\
\text { additional atrial ablation in } 50 \% \text { of } \\
\text { the cases }\end{array}$ & & $\begin{array}{l}\text { - Atrial arrhythmia freedom after } \\
1 \text {-year follow-up } \\
\circ 74 \%=\text { symptomatic arrhythmia } \\
\circ 69.9 \%=\text { symptomatic and } \\
\text { asymptomatic arrhythmia } \\
\text { Contact force within the selected } \\
\text { range } \geq 80 \% \text { of the time } \\
\text { significantly increased the } 12 \\
\text { month AF/AT freedom ( } 88 \% \text { vs. } \\
66 \% \text { ) }\end{array}$ \\
\hline $\begin{array}{l}\text { STAR-AF study } \\
\text { Verma et al., } 2015\end{array}$ & 589 PsAF & $\begin{array}{l}\text { 67: CPVI, } \\
\text { 263: CPVI plus CFAE, } \\
\text { 259: CPVI plus linear lesions (roof, } \\
\text { mitral isthmus) }\end{array}$ & & $\begin{array}{l}\text { CPVI + CFAE and CPVI + lines were } \\
\text { not superior to CPVI alone after 18\% } \\
\text { follow-up (AF freedom }=49,46,59 \% \\
\text { respectively, } P=0.15 \text { ) }\end{array}$ \\
\hline $\begin{array}{l}\text { CHASE-AF trial } \\
\text { Vogler et al., } 2015\end{array}$ & 153 PsAF & $\begin{array}{l}78 \text { pts } \mathrm{PVI} \text { alone, } \\
75 \text { full defragmentation, }\end{array}$ & $\begin{array}{l}\text { - } \mathrm{PVI} \text { group: SR achieved with } \\
\text { electrical cardioversion } \\
\text { - Full defragmentation group: AF } \\
\text { termination in } 60 \% \text { (AT=60\%, } \\
\text { SR }=40 \% \text { ) }\end{array}$ & $\begin{array}{l}\text { No difference in the AF freedom after } \\
\text { 1-year follow-up: } 61.4 \% \text { in the PVI } \\
\text { group, vs. } 58.3 \% \text { in the full-defrag } \\
\text { group }\end{array}$ \\
\hline $\begin{array}{l}\text { FIRE AND ICE trial } \\
\text { Kuck et al., } 2016 a\end{array}$ & 762 PAF & $\begin{array}{l}\text { 378: PVI using cryoablation } \\
\text { 384: Segmental PVI using } \\
\text { radiofrequency ablation }\end{array}$ & $\begin{array}{l}\text { - Successful PVI } \\
\text { - } 97.9 \% \text { in radiofrequency group } \\
\text { - } 98.9 \% \text { in the cryoballoon group }\end{array}$ & $\begin{array}{l}\text { - AF and AT freedom without } \\
\text { anti-arrhythmic drugs after a mean } \\
\text { of } 1.5 \text {-year follow-up was not } \\
\text { different between the two groups: } \\
\circ 65.4 \% \text { in the cryoballoon group } \\
\circ 64.1 \% \text { in the radiofrequency } \\
\text { group }\end{array}$ \\
\hline $\begin{array}{l}\text { Alster-Lost-AF Trial } \\
\text { Fink et al., } 2017\end{array}$ & $\begin{array}{l}\text { - } 69 \text { PsAF 6- } 12 \\
\text { months } \\
49 \text { PsAF } \geq 12 \\
\text { months }\end{array}$ & $\begin{array}{l}\text { - } 61 \text { pts CPVI-only } \\
\text { - } 57 \text { pts Substrate-modification } \\
\text { group, (CPVI + CFAEs and linear } \\
\text { ablation) }\end{array}$ & $\begin{array}{l}\text { - } \text { AF termination } \\
\circ \mathrm{CPVI} \text { alone }=3 \% \\
\circ \text { Substrate modificatio } n=19 \% \\
(P=0.007)\end{array}$ & $\begin{array}{l}\text { - AF freedom after } 1 \text { year } \\
\text { follow-up and a single } \\
\text { procedure without AAD: } \\
\circ 39 \% \text { in the CPVI group } \\
\circ 323 \% \text { in the substrate } \\
\text { modification group } \\
\text { - AF freedom after 1-year follow-up } \\
\text { and a single procedure } \pm \text { AAD: } \\
\circ 54 \% \text { in the CPVI group } \\
\circ 57 \% \text { in the substrate modification } \\
\text { group } \\
\text { - AF freedom after 1-year follow-up } \\
\text { and multiple procedures } \\
\text { - } 69 \% \text { in the CPVI group } \\
\text { - } 86 \% \text { in the substrate modification } \\
\text { group }\end{array}$ \\
\hline
\end{tabular}


TABLE 1 | Continued

\begin{tabular}{|c|c|c|c|c|}
\hline References & Population & Ablation technique & Acute results/main findings & Long term outcome \\
\hline $\begin{array}{l}\text { CASTLE AF trial } \\
\text { Marrouche et al., } 2018\end{array}$ & $\begin{array}{l}\text { - } 363 \text { pts NYHA } \\
\text { II,III,IV with PAF } \\
\text { or PsAF, LVEF } \\
\leq 35 \% \text { and an } \\
\text { ICD } \\
\text { - } 118 \text { PAF } \\
\text { - } 245 \text { PsAF } \\
\text { - } 106 \text { PsAF > } \\
\text { 12months }\end{array}$ & $\begin{array}{l}\text { - Ablation }=179 \text { pts vs. medical } \\
\text { therapy= } 184 \\
\text { - Ablation consisted in PVI plus } \\
\text { additional lesions at the discretion } \\
\text { of the operator }\end{array}$ & & $\begin{array}{l}\text { - Ablation significantly reduced death } \\
\text { from any cause and hospitalizations } \\
\text { for worsening heart failure } \\
\circ 28.5 \% \text { after ablation } \\
\circ 44.6 \% \text { with medical treatment } \\
\text { (hazard ratio, } 0.62 ; 95 \% \text { confidence } \\
\text { interval, } 0.43 \text { to } 0.87 ; P=0.007 \text { ) }\end{array}$ \\
\hline Tllz et al., 2018 & $161 \mathrm{PAF}$ & $\begin{array}{l}\text { CPVI using EAM and double-Lasso } \\
\text { technique }\end{array}$ & $\begin{array}{l}\text { - All PVI were isolated during the } \\
\text { index procedure } \\
\text { - Up to } 5 \text { redo procedures were } \\
\text { performed } \\
\text { - Recurrence were mainly due to PV } \\
\text { reconnections }\end{array}$ & $\begin{array}{l}\text { - } 10 \text {-year AF freedom } \\
\circ 32.9 \% \text { after a single procedure } \\
\circ 62.7 \% \text { after multiple procedures } \\
\text { - } 6.2 \% \text { progression to persistent AF } \\
\text { after } 10 \text { years }\end{array}$ \\
\hline Oral et al., 2007 & $100 \mathrm{PsAF}$ & CFAE ablation & $\begin{array}{l}\text { Acute termination without } \\
\text { antiarrhythmic drug: } 16 \%\end{array}$ & $\begin{array}{l}\text { - } \text { AF freedom after } 14 \pm 7 \text { months = } \\
33 \% \\
\text { - } \text { Redo ablation }=44 \% \\
\text { - Overall } \mathrm{AF} \text { freedom after } 13 \pm 7 \\
\text { months }=57 \%\end{array}$ \\
\hline Oral et al., 2009 & $\begin{array}{l}119 \text { long lasting } \\
\text { PSAF }\end{array}$ & $\begin{array}{l}\text { - } 19 \text { PVI } \\
\text { - } 50 \text { CFAE ablation } \\
\text { - } 50 \text { cardioversion }\end{array}$ & $\begin{array}{l}\text { - } \mathrm{AF} \text { termination by PVI only= } 16 \% \\
\text { - Acute } \mathrm{AF} \text { termination during CFAE } \\
\text { ablatio } n=18 \%\end{array}$ & $\begin{array}{l}\text { AF freedom after } 1 \text { procedure: } 36 \% \text { in } \\
\text { the absence of CFAE ablation and } \\
34 \% \text { after CFAE ablation (P=NS) } \\
\rightarrow \text { No benefit of additional CFAE } \\
\text { ablation }\end{array}$ \\
\hline Faustino et al., 2015 & PAF: 150 & $\begin{array}{l}\text { - } 75 \text { PVI alone } \\
\text { - } 75 \text { PVI + stepwise ablation (CFAEs } \\
\text { + linear ablation) }\end{array}$ & $\begin{array}{l}\text { - AF termination and non-inducibility } \\
\text { achieved in 100\% of the stepwise } \\
\text { approach }\end{array}$ & $\begin{array}{l}\text { - AF freedom after a first procedure } \\
\text { at } 1 \text {-year follow up significantly } \\
\text { higher in the stepwise group: } \\
\circ 73,3 \% \text { in the stepwise group } \\
\circ 53.3 \% \text { after } \mathrm{PVI}(p<0.01) \\
\text { - Similar results after a second } \\
\text { procedure }\end{array}$ \\
\hline Seitz et al., 2017 & $\begin{array}{l}33 \mathrm{PAF} \\
119 \mathrm{PsAF}\end{array}$ & $\begin{array}{l}\text { - } 105=\text { ablation only regions } \\
\text { displaying electrogram dispersion } \\
\text { during AF } \\
\text { - } 47=\mathrm{PVI} \text { and stepwise approach }\end{array}$ & $\begin{array}{l}\text { - Ablation only at dispersion areas } \\
\text { terminated AF in } 95 \% \text { of the pts. } \\
\mathrm{PVI} / \text { stepwise approach terminated } \\
\mathrm{AF} \text { in } 60 \% \text { of the pts }\end{array}$ & $\begin{array}{l}\text { - AF freedom after a mean of } 1.5 \\
\text { procedures per patient procedures } \\
\text { after } 18 \text { month-follow-up: } \\
\circ 85 \%=\text { ablation only at regions } \\
\text { displaying electrogram dispersion } \\
\text { - } 59 \%=\text { PVI/Stepwise approach } \\
(P<0.001)\end{array}$ \\
\hline
\end{tabular}


TABLE 1 | Continued

\begin{tabular}{|c|c|c|c|c|}
\hline References & Population & Ablation technique & Acute results/main findings & Long term outcome \\
\hline \multicolumn{5}{|c|}{ ROTOR ABLATION AND FIRM ABLATION } \\
\hline Cuculich et al., 2010 & $\begin{array}{l}\text { - PAF: } 11 \\
\text { - PsAF } \leq 12 \\
\text { months: } 19 \\
\text { - PsAF >12 } \\
\text { months: } 6\end{array}$ & Driver domains identified by ECGi & $\begin{array}{l}\text { - Multiple wavelets: most common } \\
\text { pattern (92\% of the patients) } \\
\text { - Rotor activity detected in only } 15 \% \\
\text { of the cases and only in patients } \\
\text { with PsAF } \\
\text { - AF complexity increased with the } \\
\text { AF duration }\end{array}$ & $\mathrm{N} / \mathrm{A}$ \\
\hline Haissaguerre et al., 2014 & $\begin{array}{l}\text { - } \text { PsAF in } \mathrm{SR}=26 \\
\text { - } \text { PSAF } \mathrm{AF} \leq 12 \\
\text { months }=57 \\
\text { - } \text { PSAF }>12 \\
\text { months }=20\end{array}$ & Driver domains identified by ECGi & $\begin{array}{l}80 \% \text { AF termination after } 28 \pm \\
\text { minutes of RF ablation. AF complexity } \\
\text { increased with AF duration }\end{array}$ & $\begin{array}{l}85 \% \text { AF freedom at } 12 \text { months in } \\
\text { group, no difference compared to the } \\
\text { control group }\end{array}$ \\
\hline Lim et al., 2017 & $\begin{array}{l}\text { - } \text { PsAF in } \mathrm{SR}=32 \\
\text { - } \text { PsAF } \mathrm{AF} \leq 12 \\
\text { months }=45 \\
\text { - } \text { PsAF }>12 \\
\text { months }=28\end{array}$ & Driver domains identified by ECGi & $\begin{array}{l}\text { - } 70 \% \text { AF termination, } \\
\text { - Increased AF complexity and } \\
\text { reduced success rate with the } \\
\text { increase of AF duration }\end{array}$ & NA \\
\hline Knecht et al., 2017 & $\begin{array}{l}\text { - } \text { PsAF in } \mathrm{SR}=32 \\
\text { - } \text { PsAF } \mathrm{AF} \leq 12 \\
\text { months }=45\end{array}$ & $\begin{array}{l}\text { Driver domains identified by ECGi in } 8 \\
\text { different centers }\end{array}$ & $\begin{array}{l}64 \% \text { AF termination after } 46 \pm 28 \text { min } \\
\text { RF ablation }\end{array}$ & $\begin{array}{l}\text { - AF freedom after } 1 \text {-year follow-up } \\
\text { was } 77 \% \\
\text { - Of the patients with no AF } \\
\text { recurrence, } 49 \% \text { experienced at } \\
\text { least one episode of atrial } \\
\text { tachycardia (AT) which required } \\
\text { either continued AAD therapy, } \\
\text { cardioversion, or repeat ablation }\end{array}$ \\
\hline Narayan et al., 2012b & $\begin{array}{l}\text { - } \mathrm{PAF}=31 \\
\text { - } \mathrm{PSAF}=76\end{array}$ & $\begin{array}{l}\text { FIRM guided: } 36 \\
\text { Conventional ablation: } 71\end{array}$ & $\begin{array}{l}\text { FIRM guided AF termination in } 56 \% \\
\text { of the cases vs. } 9 \% \text { with conventional } \\
\text { ablation }\end{array}$ & $\begin{array}{l}82 \% \text { in the FIRM guided ablation vs. } \\
45 \% \mathrm{AF} \text { freedom after } 9 \text { months }\end{array}$ \\
\hline Pappone et al., 2018 & PsAF: 81 & $\begin{array}{l}\text { - Group I: ablation of } \\
\text { repetitive-regular activities followed } \\
\text { by modified CPVI (mapping group; } \\
n=41 \text { ) } \\
\text { - Group II: modified CPVI (control } \\
\text { group; } n=40 \text { ) }\end{array}$ & $\begin{array}{l}61 \%(25 / 41) \text { AF termination in the } \\
\text { mapping- guided ablation vs. } 30 \% \\
(12 / 40) \text { with conventional strategy } \\
(P<0.007)\end{array}$ & $\begin{array}{l}\text { - AF freedom after 1-year follow-up } \\
\circ 73.2 \% \text { AF-free recurrence in the } \\
\text { mapping group } \\
\circ 50 \% \text { in the control group } \\
(P=0.03)\end{array}$ \\
\hline Cochet et al., 2018 & $\mathrm{PSAF}=41$ & $\begin{array}{l}\text { Driver domains identified using ECGi } \\
\text { during AF }\end{array}$ & $\begin{array}{l}\text { - Left atrial (LA)LGE imaging } \\
\text { significantly associated with the } \\
\text { number of re-entrant regions } \\
\text { ( } \mathrm{R}=0.52 ; P=0.001) \\
\text { - Clustering of re-entrant activity at } \\
\text { LGE borders } \\
\text { - Areas with high re-entrant activity } \\
\text { showed higher local LGE density as } \\
\text { compared with the remaining atrial } \\
\text { areas } \\
\text { - Failure to achieve AF termination } \\
\text { during ablation was associated } \\
\text { with higher LA LGE burden, higher } \\
\text { number of re-entrant regions and } \\
\text { longer AF duration }\end{array}$ & $\begin{array}{l}\text { AF freedom after } 11+/ 12 \\
\text { month-follow-up } 25 / 34(74 \%) \text { pts. }\end{array}$ \\
\hline
\end{tabular}


TABLE 1 | Continued

\begin{tabular}{|c|c|c|c|c|}
\hline References & Population & Ablation technique & Acute results/main findings & Long term outcome \\
\hline \multicolumn{5}{|l|}{ LINEAR ABLATION } \\
\hline Jais et al., 2004 & $\mathrm{PAF}=100$ & $\mathrm{PVI}+\mathrm{Ml}$ line vs. $\mathrm{PVI}+\mathrm{CTI}$ line & $\begin{array}{l}\text { PVI was achieved in all the pts, } \\
\text { Ml block was achieved in } 92 \% \text { of the } \\
\text { pts }\end{array}$ & $\begin{array}{l}87 \% \text { AF freedom without anti } \\
\text { arrhythmic drugs after MI ablation } \\
\text { after 1-year follow-up vs. } 69 \text { in the } \\
\text { PVI group }\end{array}$ \\
\hline Fassini et al., 2005 & $\begin{array}{l}\text { - } \mathrm{PAF}=126 \\
\text { - } \mathrm{PSAF}=61\end{array}$ & $\begin{array}{l}\text { Randomization: } 92 \text { PVI vs. } 95 \text { PVI + } \\
\text { MI line }\end{array}$ & $\begin{array}{l}\text { Ml block was achieved in } 72 \% \text { of the } \\
\text { pts }\end{array}$ & $\begin{array}{l}\text { AF freedom at } 1 \text {-year follow-up: } \\
\text { PsAF: } 74 \% \text { after Ml line vs. } 36 \%, p< \\
0.01 \\
\text { PAF: } 76 \% \text { after Ml line vs. } 62 \%, p< \\
0.05\end{array}$ \\
\hline Hocini et al., 2005 & - $\mathrm{PAF}=90$ & $\begin{array}{l}\text { - } \mathrm{PVI}+\text { roof line } \\
\text { - } \mathrm{PVI} \\
\text { - } \text { Ablation of CTI and ostial PV } \\
\text { fragmented signals and non PV } \\
\text { triggers in all cases }\end{array}$ & $\begin{array}{l}\text { Roof line blocked in } 96 \% \text { of the cases } \\
\text { Perimitral flutter inducible in } 22 \% \text { of } \\
\text { the cases }\end{array}$ & $\begin{array}{l}87 \% \text { Af freedom after roof line after } \\
15 \text { month-follow-up vs. } 69 \% \text { in the PVI } \\
\text { group }\end{array}$ \\
\hline Gaita et al., 2008 & $\begin{array}{l}\text { - } P A F=125 \\
\text { - } P s A F \text { and long } \\
\text { lasting } \\
\text { PsAF }=79\end{array}$ & $\begin{array}{l}\text { - } 67 \text { PVI alone (41 PAF + } 26 \text { PsAF) } \\
\text { - } 137 \text { PVI plus left linear lesions (84 } \\
\text { PAF + 53PsAF/Long-standing AF) }\end{array}$ & $\begin{array}{l}\text { - } \mathrm{PVI} \text { was acutely achieved in all pts. } \\
\text { - } \mathrm{MI} \text { block in } 31 \% \text { of the cases } \\
\text { - } \text { Roof block in } 92 \% \text { of the cases } \\
\text { - CTI block in all patients }\end{array}$ & 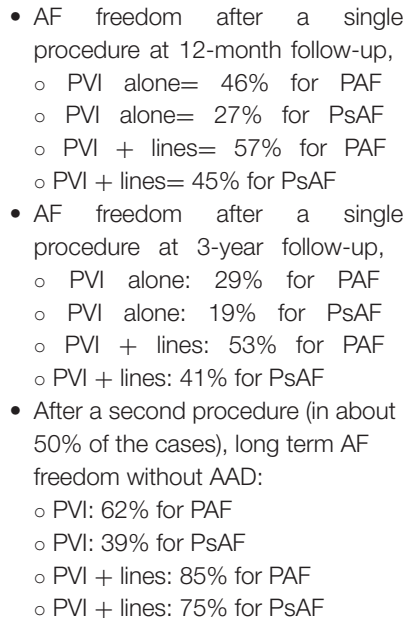 \\
\hline Mun et al., 2012 & - $\mathrm{PAF}=156$ & $\begin{array}{l}\text {-52 = CPVI, } \\
\text { - } 52=\text { CPVI+ roof line } \\
\text { - } 52=\text { CPVI+ posterior box }\end{array}$ & $\begin{array}{l}\text { - } \mathrm{CPVI}=100 \% \\
\text { - } \mathrm{CPVI}+\text { Roof line block }=80.8 \% \\
\text { - } \mathrm{CPVI}+\text { posterior box }=59.6 \%\end{array}$ & $\begin{array}{l}\text { - AF freedom after } 15.6 \pm 5 \text { months } \\
\text { of follow-up, } \\
\circ 88.5 \%=\mathrm{CPVI} \\
\circ 78.8 \%=\mathrm{CPVI}+\text { roof line } \\
\circ 80.8 \%=\mathrm{CPVI}+\text { posterior } \\
(P=0.44)\end{array}$ \\
\hline Kim et al., 2015 & - $\mathrm{PAF}=100$ & $\begin{array}{l}\text { - } 50 \text { CPVI } \\
\text { - } 50 \text { CPVI + posterior box lesion and } \\
\text { anterior linear ablation }\end{array}$ & $\begin{array}{l}\text { - } \mathrm{CPVI}+\mathrm{CTI} \text { block=100\% } \\
\text { - Anterior Line block=68\% } \\
\text { - } \text { Posterior box isolatio } n=60 \%\end{array}$ & $\begin{array}{l}\text { - AF freedom after } 16.3 \pm 4 \text {-month } \\
\text { follow-up without AAD: } \\
\circ \mathrm{CPVI}=88 \% \\
\circ \mathrm{CPVI}+\text { posterior box + anterior } \\
\text { line }=84 \%\end{array}$ \\
\hline Kettering et al., 2017 & $P s A F=250$ & $\begin{array}{l}\text { - } \mathrm{CPVI}+\text { roof line } \\
\text { - } \mathrm{CPVI} \text { alone } \\
\text { - Additional MI line (6 pts), and right } \\
\text { atrial ablation (11 pts) }\end{array}$ & - Roof blocked in all cases & $\begin{array}{l}\text { - AF freedom after } 1 \text {-year follow-up } \\
\circ 81 \% \text { after roof line vs. } \\
\circ 74 \% \text { after } \mathrm{PVI}(\mathrm{p}=\mathrm{NS}) \\
\text { - } \mathrm{AF} \text { freedom after } 3 \text {-year follow-up } \\
\circ 72 \% \text { after roof line } 63 \% \text { after } \mathrm{PVI} \text {, } \\
P=0.04\end{array}$ \\
\hline \multicolumn{5}{|c|}{ SUBSTRATE MODIFICATION (FIBROTIC AREAS AND LOW VOLTAGE AREAS) } \\
\hline Jadidi et al., 2016 & $\mathrm{PSAF}=151$ & $\begin{array}{l}\text { - Group 1: 85: PVI + ablation at } \\
\text { low-voltage areas (LVA <0.5 mV in } \\
\text { AF) with fractionated activity or } \\
\text { rotational activity or discrete rapid } \\
\text { local activity } \\
\text { - Group 2: } 66 \text { : PVI (control group) }\end{array}$ & $\begin{array}{l}\text { - AF termination targeting LVAs with } \\
\text { specific electrogram patterns = } \\
73 \% \\
\text { - AF termination sites colocalized } \\
\text { within LVA in } 80 \% \text { and at border } \\
\text { zones in } 20 \%\end{array}$ & $\begin{array}{l}\text { - Single- procedural AF-free survival } \\
\text { after } 13 \text {-month follow-up } \\
\circ 69 \%=\text { group } 1 \\
\circ 47 \%=\text { group } 2(P<0.001)\end{array}$ \\
\hline
\end{tabular}


TABLE 1 | Continued

\begin{tabular}{|c|c|c|c|c|}
\hline References & Population & Ablation technique & Acute results/main findings & Long term outcome \\
\hline Yamaguchi et al., 2016 & $\mathrm{PsAF}=117$ & $\begin{array}{l}\text { - Group I: } 101=\text { targeting } \\
\text { low-voltage areas (<0.5 mV in SR) } \\
\circ \text { Group la:39 = PVI + ablation of } \\
\text { LVA } \\
\text { ○Group Ib:62 = PVI only (LVA not } \\
\text { identified) } \\
\text { - Group II: } 16=\text { LVA non ablated } \\
\text { group, only PVI }\end{array}$ & $\begin{array}{l}\text { - Complete low voltage areas } \\
\text { elimination in } 92 \% \text { of the cases } \\
\text { - Additional linear lesions in } 82 \% \text { of } \\
\text { the cases in group la }\end{array}$ & $\begin{array}{l}\text { - AF freedom after a single } \\
\text { procedure after } 18 \pm 7 \text { months } \\
\circ 72 \%=\text { No LVA identified } \\
\circ 79 \% \text { LVA ablation } \\
\circ 38 \% \text { No LVA ablation }\end{array}$ \\
\hline $\begin{array}{l}\text { BIFA trial } \\
\text { Schreiber et al., } 2017\end{array}$ & $\begin{array}{l}\text { - } \mathrm{PAF}=34 \\
\text { - } \mathrm{PSAF}=49 \\
\text { - } \text { Long lasting } \\
\text { PSAF }=9\end{array}$ & $\begin{array}{l}\text { - } 92 \mathrm{PVI}+\text { box isolation of fibrotic } \\
\text { area (BIFA) (<0.5 mV bipolar } \\
\text { signals in sinus rhythm) } \\
\text { - } 49 \mathrm{PVI} \text { (no fibrotic area identified } \\
\text { during mapping) }\end{array}$ & $\begin{array}{l}\text { - Different stages of Fibrotic atrial } \\
\text { cardiomyopathy (FACM) } \\
\circ 0=\text { no detectable voltage }<1.5 \\
\mathrm{mV} \\
\circ \mathrm{I}=\text { very limited severe fibrosis } \\
\circ \|=\text { confluence scar fibrotic areas } \\
(<0.5 \mathrm{mV} \text { ) } \\
\circ \mathrm{III}=\text { pronounced } \geq 2 \text { scar fibrotic } \\
\text { areas (<0.5 mV) } \\
\text { - IV }=\text { diffuse fibrosis ("strawberry") }\end{array}$ & $\begin{array}{l}\text { - AF freedom after } 16 \pm 8 \text { months } \\
\circ \quad \text { Single procedure=69\% } \\
\circ \text { Multiple procedures }=83 \% \\
\text { - The extent of fibrosis significantly } \\
\text { associated to AF recurrence }\end{array}$ \\
\hline $\begin{array}{l}\text { STABLE SR } \\
\text { Yang et al., } 2017\end{array}$ & PsAF=229 pts & $\begin{array}{l}\text { - STABLE-SR group: } 114=\mathrm{CPVI}+ \\
\text { CTI + ablation-homogenization of } \\
\text { areas with low-voltage (LVZ } \\
0.1-0.4 \mathrm{mV} \text { in SR) and complex } \\
\text { electrograms } \\
\text { - Stepwise group:115= CPVI + } \\
\text { linear lesions + CFAEs }\end{array}$ & $\begin{array}{l}\text { - } \text { AF termination in STABLER-SR } \\
\text { group }=12.3 \% \\
\text { - } \text { AF termination in stepwise } \\
\text { group }=32.5 \%\end{array}$ & $\begin{array}{l}\text { AF-free survival after } 18 \text {-month } \\
\text { follow-up } \\
\text { STABLE-SR group: } 74 \% \\
\text { Stepwise group: } 71.5 \%(P=0.325)\end{array}$ \\
\hline
\end{tabular}

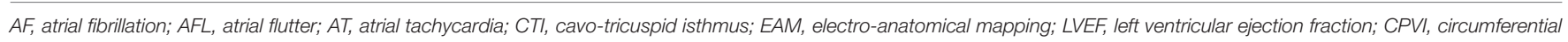
pulmonary veins isolation; MI, mitral isthmus; PAF, paroxysmal AF; PSAF, persistent AF; PVI, pulmonary veins isolation.

to $53-68 \%$ at 5 years (Neumann et al., 2013; Takigawa et al., 2015a, 2017; Kis et al., 2017). The long term freedom from AF may reach 77\% (Vogt et al., 2013) after redo PVI. AF recurrence may be related to non PV triggers in one half of cases (Takigawa et al., 2015b) and to the reconnection of the PVs in the remaining cases.

Substrate modification in addition to PVI was tested by Di Biase et al. (2009) who randomly assigned 103 consecutive patients undergoing PAF to PVI alone $(n=35)$, PVI followed by CFAE ablation $(n=34)$ or CFAE ablation alone $(n=$ 34). There was no difference in terms of success rate between PVI alone and PVI followed by CFAE ablation. However, CFAE ablation alone was associated with the highest rates of AF recurrence after 1-year follow-up. Similar results were reported in subsequent studies (Deisenhofer et al., 2009; Chen et al., 2011; Hayward et al., 2011). In addition, techniques aiming at incomplete PVI (Kuck et al., 2016b) or not isolating PV (Mikhaylov et al., 2011) were associated to worse results.

\section{CFAE Ablation}

Targeting the complex fractionated signals was commonly used as a strategy to ablate PsAF forms. Originally in 2004; Nademanee et al. (2004) included 121 patients with paroxysmal AF (57 patients) or chronic AF (64 patients) and performed ablation by targeting fragmented electrograms without additional PVI. They reported a high rate of acute success by targeting areas of CFAE (without PVI) with $95 \%$ of AF termination by ablation (associated to ibutilide in $28 \%$ of the cases) and $76 \%$ of $\mathrm{AF}$ freedom at 1-year follow-up after one procedure. However, this result was not reproduced by Oral et al. (2007) who included 100 patients with chronic AF where they ablated CFAEs in the left atrium and the coronary sinus without performing PVI. Only 33\% of the patients were free from AF or AT recurrence after a follow-up of $14 \pm 7$ months after one procedure. A second procedure was performed in $44 \%$ of the patients, pulmonary vein tachycardia originating from the targeted veins sustained atrial tachycardia in all cases.

Oral et al. (2009) performed a randomized study and included 119 consecutive patients with long-lasting PsAF. All patients underwent PVI that allowed termination to sinus rhythm in 19 (16\%) of the cases. In the remaining 100 cases, patients were equally assessed to either electrical cardioversion or ablation of the CFAE in the left atrium or the coronary sinus. After $10 \pm$ 3-month follow-up, there was no difference in the rate of sinus rhythm without anti-arrhythmic drugs between the 3 groups.

In the STAR AF II study, Verma et al. (2015) performed a prospective randomized multicenter study that included 589 patients with PsAF. Ablation consisted in PVI alone in 67 patients, PVI and ablation of complex fractionated electrograms (263 patients) or PVI and additional linear ablation (259 patients). Acute termination of AF during ablation was significantly higher in patients undergoing PVI and complex electrograms ablation or PVI and linear ablation than patients undergoing PVI alone. However, the freedom from AF was not different between the three groups. 


\section{AF Drivers' Ablation}

In a recent meta-analysis, Parameswaran et al. (2018) analyzed the outcome after rotor ablation in 11 studies with a total of 556 patients undergoing FIRM ablation for paroxysmal AF $(n=166)$ or PsAF $(n=390)$. Pooled single-procedure freedom from AF was around $37.8 \%$ PAF and $59.2 \%$ for PsAF after a mean followup of 1 year. Heterogeneity between the different studies was significantly high.

In the AFACART study (Knecht et al., 2017), non-invasive mapping was used to guide the ablation for 118 patients with PsAF lasting $<1$ year. Ablation targeted the drivers identified by the system, followed by PV isolation and linear ablation when AF could not be terminated. Ablation targeting the drivers' sites terminated AF in $64 \%$ of the cases after a mean radiofrequency ablation duration of $46 \pm 28 \mathrm{~min}$. AF termination rate increased to $72 \%$ when additional PVI and atrial linear ablation were performed. Extra-PV sources played a key role in the maintenance of PsAF and their ablation is associated with the termination of AF in the majority of the cases and arrhythmia freedom up to $77 \%$ at a 1 -year follow-up.

\section{Surgical Treatment for AF}

Surgical treatment for AF was first described by Dr Cox (Cox, 1991). The surgery consisted in linear incisions of the atrial walls that aimed to interrupt the multiple wavelets and reentrant circuits and subsequently direct atrial activation through a mazelike system involving both atria. Different surgical techniques were developed later (Fragakis et al., 2012; Xu et al., 2016), all associated to high rates of arrhythmia free outcome (Prasad et al.,

\section{REFERENCES}

Abed, H. S., Samuel, C. S., Lau, D. H., Kelly, D. J., Royce, S. G., Alasady, M., et al. (2013). Obesity results in progressive atrial structural and electrical remodeling: implications for atrial fibrillation. Heart Rhythm. 10, 90-100. doi: 10.1016/j.hrthm.2012.08.043

Ajijola, O. A., Wisco, J. J., Lambert, H. W., Mahajan, A., Stark, E., Fishbein, M. C., et al. (2012). Extracardiac neural remodeling in humans with cardiomyopathy. Circ. Arrhythm. Electrophysiol. 5, 1010-1116. doi: 10.1161/CIRCEP.112. 972836

Ajijola, O. A., Yagishita, D., Reddy, N. K., Yamakawa, K., Vaseghi, M., Downs, A. M., et al. (2015). Remodeling of stellate ganglion neurons after spatially targeted myocardial infarction: neuropeptide and morphologic changes. Heart Rhythm. 12, 1027-1035. doi: 10.1016/j.hrthm.2015.01.045

Akoum, N., Wilber, D., Hindricks, G., Jais, P., Cates, J., Marchlinski, F., et al. (2015). MRI Assessment of ablation-induced scarring in atrial fibrillation: analysis from the DECAAF study. J. Cardiovasc. Electrophysiol. 26, 473-480. doi: $10.1111 /$ jce. 12650

Allessie, M., Ausma, J., and Schotten, U. (2002). Electrical, contractile and structural remodeling during atrial fibrillation. Cardiovasc. Res. 54, 230-246. doi: 10.1016/S0008-6363(02)00258-4

Allessie, M. A., Bonke, F. I., and Schopman, F. J. (1977). Circus movement in rabbit atrial muscle as a mechanism of tachycardia. III. The "leading circle" concept: a new model of circus movement in cardiac tissue without the involvement of an anatomical obstacle. Circ Res. 41, 9-18. doi: 10.1161/01.RES.41.1.9

Alonso, S., and Bar, M. (2013). Reentry near the percolation threshold in a heterogeneous discrete model for cardiac tissue. Phys. Rev. Lett. 110:158101. doi: 10.1103/PhysRevLett.110.158101

Alonso, S., Dos Santos, R. W., and Bär, M. (2016). Reentry and ectopic pacemakers emerge in a three-dimensional model for a slab of cardiac tissue with
2003; Ballaux et al., 2006; Barnett and Ad, 2006; Weimar et al., 2012; Gillinov et al., 2015).

Hybrid approach (Tahir et al., 2018) overcomes the limitations of the catheter based ablation and of the surgical ablation. Epicardial thoracoscopic ablation followed by endocardial ablation is associated to high rates of long term freedom from AF recurrence exceeding $70 \%$ in patients with paroxysmal or PsAF (Krul et al., 2011; Pison et al., 2012, 2014; La Meir et al., 2013; Kurfirst et al., 2014; Bulava et al., 2015).

\section{CONCLUSION}

Mechanisms underlying AF are complex and remain incompletely understood despite extensive research. Translating AF mechanisms described in basic science to the clinical practice remains challenging. In contrast with PAF, therapeutic interventions for PsAF are still inadequate, mainly limited by the identification of the sources maintaining AF. PsAF is driven by focal and reentrant activity which are initially clustered in a relatively limited atrial surface. These drivers disseminate everywhere because of the atrial remodeling which increases the complexity of AF. Accurate mapping techniques that consider the spatio-temporal variation of $\mathrm{AF}$ are essential to identify these sources.

\section{AUTHOR CONTRIBUTIONS}

All authors listed have made a substantial, direct and intellectual contribution to the work, and approved it for publication. diffuse microfibrosis near the percolation threshold. PLoS ONE 11:e0166972. doi: 10.1371/journal.pone.0166972

Amraoui, S., Pomier, C., Sacher, F., Derval, N., Denis, A., Massoullié, G., et al. (2016). 209-05: does flecainide pre-treatment helps to identify the most important players? EP Europace 18, i141-i141. doi: 10.1093/europace/18.suppl_1.i141

Anter, E., Di Biase, L., Contreras-Valdes, F. M., Gianni, C., Mohanty, S., Tschabrunn, C. M., et al. (2017). Atrial substrate and triggers of paroxysmal atrial fibrillation in patients with obstructive sleep apnea. Circ. Arrhythm. Electrophysiol. 10:e005407. doi: 10.1161/CIRCEP.117.005407

Arentz, T., Haegeli, L., Sanders, P., Weber, R., Neumann, F. J., Kalusche, D., et al. (2007). High-density mapping of spontaneous pulmonary vein activity initiating atrial fibrillation in humans. J. Cardiovasc. Electrophysiol. 18, 31-38. doi: 10.1111/j.1540-8167.2006.00682.x

Arentz, T., Von Rosenthal, J., Blum, T., Stockinger, J., Burkle, G., Weber, R., et al. (2003). Feasibility and safety of pulmonary vein isolation using a new mapping and navigation system in patients with refractory atrial fibrillation. Circulation 108, 2484-2490. doi: 10.1161/01.CIR.0000097118.75179.83

Armour, J. A. (2008). Potential clinical relevance of the 'little brain' on the mammalian heart. Exp. Physiol. 93, 165-176. doi: 10.1113/expphysiol.2007.041178

Armour, J. A., Murphy, D. A., Yuan, B. X., Macdonald, S., and Hopkins, D. A. (1997). Gross and microscopic anatomy of the human intrinsic cardiac nervous system. Anat Rec. 247, 289-298.

Arora, R. (2012). Recent insights into the role of the autonomic nervous system in the creation of substrate for atrial fibrillation - implications for therapies targeting the atrial autonomic nervous system. Circ. Arrhythm. Electrophysiol. 5, 850-859. doi: 10.1161/CIRCEP.112.972273

Arora, R., Ulphani, J. S., Villuendas, R., Ng, J., Harvey, L., Thordson, S., et al. (2008). Neural substrate for atrial fibrillation: implications for targeted 
parasympathetic blockade in the posterior left atrium. Am. J. Physiol. Heart Circ. Physiol. 294, H134-H144. doi: 10.1152/ajpheart.00732.2007

Atienza, F., Almendral, J., Ormaetxe, J. M., Moya, A., Martinez-Alday, J. D., Hernandez-Madrid, A., et al. (2014). Comparison of radiofrequency catheter ablation of drivers and circumferential pulmonary vein isolation in atrial fibrillation: a noninferiority randomized multicenter RADAR-AF trial. J. Am. Coll. Cardiol. 64, 2455-2467. doi: 10.1016/j.jacc.2014.09.053

Badger, T. J., Daccarett, M., Akoum, N. W., Adjei-Poku, Y. A., Burgon, N. S., Haslam, T. S., et al. (2010). Evaluation of left atrial lesions after initial and repeat atrial fibrillation ablation: lessons learned from delayed-enhancement MRI in repeat ablation procedures. Circ. Arrhythm. Electrophysiol. 3, 249-259. doi: 10.1161/CIRCEP.109.868356

Ballaux, P. K., Geuzebroek, G. S., Van Hemel, N. M., Kelder, J. C., Dossche, K. M., Ernst, J. M., et al. (2006). Freedom from atrial arrhythmias after classic maze III surgery: a 10-year experience. J. Thorac. Cardiovasc. Surg. 132, 1433-1440. doi: $10.1016 /$ j.jtcvs.2006.06.048

Bapat, A., Anderson, C. D., Ellinor, P. T., and Lubitz, S. A. (2018). Genomic basis of atrial fibrillation. Heart 104, 201-206. doi: 10.1136/heartjnl-2016-311027

Barnett, S. D., and Ad, N. (2006). Surgical ablation as treatment for the elimination of atrial fibrillation: a meta-analysis. J. Thorac. Cardiovasc. Surg. 131, 1029-1035. doi: 10.1016/j.jtcvs.2005.10.020

Benharash, P., Buch, E., Frank, P., Share, M., Tung, R., Shivkumar, K., et al. (2015). Quantitative analysis of localized sources identified by focal impulse and rotor modulation mapping in atrial fibrillation. Circ. Arrhythm. Electrophysiol. 8, 554-561. doi: 10.1161/CIRCEP.115.002721

Benjamin Shoemaker, M., Muhammad, R., Parvez, B., White, B. W., Streur, M., Song, Y., et al. (2013). Common atrial fibrillation risk alleles at $4 \mathrm{q} 25$ predict recurrence after catheter-based atrial fibrillation ablation. Heart Rhythm. 10, 394-400. doi: 10.1016/j.hrthm.2012.11.012

Benjamin, E. J., Rice, K. M., Arking, D. E., Pfeufer, A., Van Noord, C., Smith, A. V., et al. (2009). Variants in ZFHX3 are associated with atrial fibrillation in individuals of European ancestry. Nat. Genet. 41, 879-881. doi: 10.1038/ng.416

Benjamin, E. J., Wolf, P. A., D'agostino, R. B., Silbershatz, H., Kannel, W. B., and Levy, D. (1998). Impact of atrial fibrillation on the risk of death: the framingham heart study. Circulation 98, 946-952. doi: 10.1161/01.CIR.98.10.946

Berte, B., Relan, J., Sacher, F., Pillois, X., Appetiti, A., Yamashita, S., et al. (2015). Impact of electrode type on mapping of scar-related VT. J. Cardiovasc. Electrophysiol. 26, 1213-1223. doi: 10.1111/jce.12761

Bray, M. A., and Wikswo, J. P. (2002). Considerations in phase plane analysis for nonstationary reentrant cardiac behavior. Phys. Rev. E Stat. Nonlin. Soft Matter Phys. 65:051902. doi: 10.1103/PhysRevE.65.051902

Buch, E., Share, M., Tung, R., Benharash, P., Sharma, P., Koneru, J., et al. (2016). Long-term clinical outcomes of focal impulse and rotor modulation for treatment of atrial fibrillation: a multicenter experience. Heart Rhythm. 13, 636-641. doi: 10.1016/j.hrthm.2015.10.031

Bulava, A., Mokracek, A., Hanis, J., Kurfirst, V., Eisenberger, M., and Pesl, L. (2015). Sequential Hybrid Procedure for Persistent Atrial Fibrillation. Journal of the American Heart Association. 4:e001754. doi: 10.1161/JAHA.114.001754

Burstein, B., and Nattel, S. (2008). Atrial fibrosis: mechanisms and clinical relevance in atrial fibrillation. J. Am. Coll. Cardiol. 51, 802-809. doi: 10.1016/j.jacc.2007.09.064

Burstein, B., Qi, X. Y., Yeh, Y. H., Calderone, A., and Nattel, S. (2007). Atrial cardiomyocyte tachycardia alters cardiac fibroblast function: a novel consideration in atrial remodeling. Cardiovasc. Res. 76, 442-452. doi: 10.1016/j.cardiores.2007.07.013

Cabo, C., Pertsov, A. M., Davidenko, J. M., Baxter, W. T., Gray, R. A., and Jalife, J. (1996). Vortex shedding as a precursor of turbulent electrical activity in cardiac muscle. Biophys. J. 70, 1105-1111.

Campbell, C. M., Campbell, J. D., Thompson, C. H., Galimberti, E. S., Darbar, D., Vanoye, C. G., et al. (2013). Selective targeting of gain-of-function KCNQ1 mutations predisposing to atrial fibrillation. Circ. Arrhythm. Electrophysiol. 6, 960-966. doi: 10.1161/CIRCEP.113.000439

Campbell, H. M., and Wehrens, X. H. T. (2018). Genetics of atrial fibrillation: an update. Curr. Opin. Cardiol. 33, 304-310. doi: 10.1097/HCO.0000000000000505

Chang, C. M., Wu, T. J., Zhou, S., Doshi, R. N., Lee, M. H., Ohara, T., et al. (2001). Nerve sprouting and sympathetic hyperinnervation in a canine model of atrial fibrillation produced by prolonged right atrial pacing. Circulation 103, 22-25. doi: 10.1161/01.CIR.103.1.22

Chen, J., Mandapati, R., Berenfeld, O., Skanes, A. C., Gray, R. A., and Jalife, J. (2000). Dynamics of wavelets and their role in atrial fibrillation in the isolated sheep heart. Cardiovasc. Res. 48, 220-232. doi: 10.1016/S0008-6363(00)00177-2

Chen, M., Yang, B., Chen, H., Ju, W., Zhang, F., Tse, H. F., et al. (2011). Randomized comparison between pulmonary vein antral isolation versus complex fractionated electrogram ablation for paroxysmal atrial fibrillation. $J$. Cardiovasc. Electrophysiol. 22, 973-981. doi: 10.1111/j.1540-8167.2011.02051.x

Chen, P.-S., Chen, L. S., Fishbein, M. C., Lin, S.-F., and Nattel, S. (2014). Role of the autonomic nervous system in atrial fibrillation: pathophysiology and therapy. Circ. Res. 114, 1500-1515. doi: 10.1161/CIRCRESAHA.114.303772

Chen, S. A., Hsieh, M. H., Tai, C. T., Tsai, C. F., Prakash, V. S., Yu, W. C., et al. (1999). Initiation of atrial fibrillation by ectopic beats originating from the pulmonary veins: electrophysiological characteristics, pharmacological responses, and effects of radiofrequency ablation. Circulation 100, 1879-1886. doi: 10.1161/01.CIR.100.18.1879

Cheniti, G., Takigawa, M., Denis, A., Thompson, N., Amraoui, S., Antonio, F., et al. (2016). 216-28: electrophysiological effects of amiodarone in patients with persistent atrial fibrillation. EP Europace 18, i148-i148. doi: 10.1093/europace/18.suppl_1.i148a

Chou, C. C., Nihei, M., Zhou, S., Tan, A., Kawase, A., Macias, E. S., et al. (2005). Intracellular calcium dynamics and anisotropic reentry in isolated canine pulmonary veins and left atrium. Circulation 111, 2889-2897. doi: 10.1161/CIRCULATIONAHA.104.498758

Christophersen, I. E., Rienstra, M., Roselli, C., Yin, X., Geelhoed, B., Barnard, J., et al. (2017). Large-scale analyses of common and rare variants identify 12 new loci associated with atrial fibrillation. Nat. Genet. 49, 946-952. doi: 10.1038/ng.3843

Cochet, H., Dubois, R., Sacher, F., Derval, N., Sermesant, M., Hocini, M., et al. (2014). Cardiac arrythmias: multimodal assessment integrating body surface ECG mapping into cardiac imaging. Radiology 271, 239-247. doi: 10.1148/radiol.13131331

Cochet, H., Dubois, R., Yamashita, S., Al Jefairi, N., Berte, B., Sellal, J. M., et al. (2018). Relationship between fibrosis detected on late gadoliniumenhanced cardiac magnetic resonance and re-entrant activity assessed with electrocardiographic imaging in human persistent atrial fibrillation. JACC Clin Electrophysiol. 4, 17-29. doi: 10.1016/j.jacep.2017.07.019

Comtois, P., and Nattel, S. (2011). Interactions between cardiac fibrosis spatial pattern and ionic remodeling on electrical wave propagation. Conf. Proc. IEEE Eng. Med. Biol. Soc. 2011, 4669-4672. doi: 10.1109/IEMBS.2011.6091156

Comtois, P., and Vinet, A. (1999). Curvature effects on activation speed and repolarization in an ionic model of cardiac myocytes. Physical Review E. 60, 4619-4628. doi: 10.1103/PhysRevE.60.4619

Correa De Sa, D. D., Thompson, N., Stinnett-Donnelly, J., Znojkiewicz, P., Habel, N., Muller, J. G., et al. (2011). Electrogram fractionation: the relationship between spatiotemporal variation of tissue excitation and electrode spatial resolution. Circ. Arrhythm. Electrophysiol. 4, 909-916. doi: 10.1161/CIRCEP.111.965145

Cox, J. L. (1991). The surgical treatment of atrial fibrillation. IV. Surgical technique. J. Thorac. Cardiovasc. Surg. 101, 584-592.

Cuculich, P. S., Wang, Y., Lindsay, B. D., Faddis, M. N., Schuessler, R. B., Damiano, R. J. Jr. et al. (2010). Noninvasive characterization of epicardial activation in humans with diverse atrial fibrillation patterns. Circulation 122, 1364-1372. doi: 10.1161/CIRCULATIONAHA.110.945709

Daccarett, M., Badger, T. J., Akoum, N., Burgon, N. S., Mahnkopf, C., Vergara, G., et al. (2011). Association of left atrial fibrosis detected by delayed-enhancement magnetic resonance imaging and the risk of stroke in patients with atrial fibrillation. J. Am. Coll. Cardiol. 57, 831-838. doi: 10.1016/j.jacc.2010. 09.049

Daoud, E. G., Zeidan, Z., Hummel, J. D., Weiss, R., Houmsse, M., Augostini, R., et al. (2017). Identification of repetitive activation patterns using novel computational analysis of multielectrode recordings during atrial fibrillation and flutter in humans. JACC Clin. Electrophysiol. 3, 207-216. doi: $10.1016 /$ j.jacep.2016.08.001

Darbar, D. (2016). The role of pharmacogenetics in atrial fibrillation therapeutics: is personalized therapy in sight? J. Cardiovasc. Pharmacol. 67, 9-18. doi: $10.1097 /$ FJC. 0000000000000280 
Darbar, D., Motsinger, A. A., Ritchie, M. D., Gainer, J. V., and Roden, D. M. (2007). Polymorphism modulates symptomatic response to antiarrhythmic drug therapy in patients with lone atrial fibrillation. Heart Rhythm. 4, 743-749. doi: 10.1016/j.hrthm.2007.02.006

Davidenko, J. M., Kent, P. F., Chialvo, D. R., Michaels, D. C., and Jalife, J. (1990). Sustained vortex-like waves in normal isolated ventricular muscle. Proc. Natl. Acad. Sci. U.S.A. 87, 8785-8789. doi: 10.1073/pnas.87.22.8785

Davidenko, J. M., Pertsov, A. V., Salomonsz, R., Baxter, W., and Jalife, J. (1992). Stationary and drifting spiral waves of excitation in isolated cardiac muscle. Nature 355, 349-351. doi: 10.1038/355349a0

De Bakker, J. M., and Wittkampf, F. H. (2010). The pathophysiologic basis of fractionated and complex electrograms and the impact of recording techniques on their detection and interpretation. Circ. Arrhythm. Electrophysiol. 3, 204-213. doi: 10.1161/CIRCEP.109.904763

De Groot, N., Van Der Does, L., Yaksh, A., Lanters, E., Teuwen, C., Knops, P., et al. (2016). Direct proof of endo-epicardial asynchrony of the atrial wall during atrial fibrillation in humans. Circ. Arrhythm. Electrophysiol. 9:e003648. doi: 10.1161/CIRCEP.115.003648

Deisenhofer, I., Estner, H., Reents, T., Fichtner, S., Bauer, A., Wu, J., et al. (2009). Does electrogram guided substrate ablation add to the success of pulmonary vein isolation in patients with paroxysmal atrial fibrillation? A prospective, randomized study. J. Cardiovasc. Electrophysiol. 20, 514-521. doi: 10.1111/j.1540-8167.2008.01379.x

Deisenhofer, I., Schneider, M. A. E., Böhlen-Knauf, M., Zrenner, B., Ndrepepa, G., Schmieder, S., et al. (2003). Circumferential mapping and electric isolation of pulmonary veins in patients with atrial fibrillation. Am. J. Cardiol. 91, 159-163. doi: 10.1016/S0002-9149(02)03102-8

Dewland, T. A., Olgin, J. E., Vittinghoff, E., and Marcus, G. M. (2013). Incident atrial fibrillation among Asians, Hispanics, Blacks, and Whites. Circulation 128, 2470-2477. doi: 10.1161/CIRCULATIONAHA.113.002449

Di Biase, L., Elayi, C. S., Fahmy, T. S., Martin, D. O., Ching, C. K., Barrett, C., et al. (2009). Atrial fibrillation ablation strategies for paroxysmal patients: randomized comparison between different techniques. Circ. Arrhythm. Electrophysiol. 2, 113-119. doi: 10.1161/CIRCEP.108.798447

Dimitri, H., Ng, M., Brooks, A. G., Kuklik, P., Stiles, M. K., Lau, D. H., et al. (2012). Atrial remodeling in obstructive sleep apnea: implications for atrial fibrillation. Heart Rhythm. 9, 321-327. doi: 10.1016/j.hrthm.2011.10.017

Eggimann, L., Blum, S., Aeschbacher, S., Reusser, A., Ammann, P., Erne, P., et al. (2018). Risk factors for heart failure hospitalizations among patients with atrial fibrillation. PLoS ONE 13:e0191736. doi: 10.1371/journal.pone.01 91736

Ehrlich, J. R., Cha, T. J., Zhang, L., Chartier, D., Melnyk, P., Hohnloser, S. H., et al. (2003). Cellular electrophysiology of canine pulmonary vein cardiomyocytes: action potential and ionic current properties. J. Physiol. 551, 801-813. doi: 10.1113/jphysiol.2003.046417

Elayi, C. S., Di Biase, L., Bai, R., Burkhardt, J. D., Mohanty, P., Santangeli, P., et al. (2013). Administration of isoproterenol and adenosine to guide supplemental ablation after pulmonary vein antrum isolation. J. Cardiovasc. Electrophysiol. 24, 1199-1206. doi: 10.1111/jce.12252

Ellinor, P. T., Lunetta, K. L., Albert, C. M., Glazer, N. L., Ritchie, M. D., Smith, A. V., et al. (2012). Meta-analysis identifies six new susceptibility loci for atrial fibrillation. Nat. Genet. 44, 670-675. doi: 10.1038/ng.2261

Ellinor, P. T., Lunetta, K. L., Glazer, N. L., Pfeufer, A., Alonso, A., Chung, M. K., et al. (2010). Common variants in KCNN3 are associated with lone atrial fibrillation. Nat. Genet. 42, 240-244. doi: 10.1038/ng.537

Enriquez, A., Liang, J. J., Santangeli, P., Marchlinski, F. E., and Riley, M. P. (2017). Focal atrial fibrillation from the superior vena cava. J. Atr. Fibrillation. 9:1593. doi: 10.4022/jafib.1593

Faggioni, M., Savio-Galimberti, E., Venkataraman, R., Hwang, H. S., Kannankeril, P. J., Darbar, D., et al. (2014). Suppression of spontaneous ca elevations prevents atrial fibrillation in calsequestrin 2-null hearts. Circ. Arrhythm. Electrophysiol. 7, 313-320. doi: 10.1161/CIRCEP.113.000994

Fassini, G., Riva, S., Chiodelli, R., Trevisi, N., Berti, M., Carbucicchio, C., et al. (2005). Left mitral isthmus ablation associated with PV Isolation: long-term results of a prospective randomized study. J. Cardiovasc. Electrophysiol. 16, 1150-1156. doi: 10.1111/j.1540-8167.2005.50192.x

Faustino, M., Pizzi, C., Agricola, T., Xhyheri, B., Costa, G. M., Flacco, M. E., et al. (2015). Stepwise ablation approach versus pulmonary vein isolation in patients with paroxysmal atrial fibrillation: randomized controlled trial. Heart Rhythm. 12, 1907-1915. doi: 10.1016/j.hrthm.2015.06.009

Fink, T., Schluter, M., Heeger, C. H., Lemes, C., Maurer, T., Reissmann, B., et al. (2017). Stand-alone pulmonary vein isolation versus pulmonary vein isolation with additional substrate modification as index ablation procedures in patients with persistent and long-standing persistent atrial fibrillation: the randomized alster-lost-AF Trial (Ablation at St. Georg Hospital for Long-Standing Persistent Atrial Fibrillation). Circ. Arrhythm. Electrophysiol. 10:e005114. doi: 10.1161/CIRCEP.117.005114

Fox, C. S., Parise, H., D’agostino, R. B. Sr, Lloyd-Jones, D. M., Vasan, R. S., Wang, T. J., et al. (2004). Parental atrial fibrillation as a risk factor for atrial fibrillation in offspring. JAMA 291, 2851-2855. doi: 10.1001/jama.291.23.2851

Fragakis, N., Pantos, I., Younis, J., Hadjipavlou, M., and Katritsis, D. G. (2012). Surgical ablation for atrial fibrillation. Europace 14, 1545-1552. doi: 10.1093/europace/eus081

Frontera, A., Cheniti, G., Martin, C. A., Takigawa, M., Duchateau, J., Puyo, S., et al. (2018a). Frontiers in non-invasive cardiac mapping: future implications for arrhythmia treatment. Minerva Cardioangiol. 66, 75-82. doi: $10.23736 / \mathrm{S} 0026-4725.17 .04463-2$

Frontera, A., Takigawa, M., Martin, R., Thompson, N., Cheniti, G., Massoullie, G., et al. (2018b). Electrogram signature of specific activation patterns: analysis of atrial tachycardias at high-density endocardial mapping. Heart Rhythm. 15, 28-37. doi: 10.1016/j.hrthm.2017.08.001

Frustaci, A., Chimenti, C., Bellocci, F., Morgante, E., Russo, M. A., and Maseri, A. (1997). Histological substrate of atrial biopsies in patients with lone atrial fibrillation. Circulation 96, 1180-1184. doi: 10.1161/01.CIR.96.4.1180

Gaita, F., Caponi, D., Scaglione, M., Montefusco, A., Corleto, A., Di Monte, F., et al. (2008). Long-term clinical results of 2 different ablation strategies in patients with paroxysmal and persistent atrial fibrillation. Circ. Arrhythm. Electrophysiol. 1, 269-275. doi: 10.1161/CIRCEP.108.774885

Ganesan, A. N., Shipp, N. J., Brooks, A. G., Kuklik, P., Lau, D. H., Lim, H. S., et al. (2013). Long-term outcomes of catheter ablation of atrial fibrillation: a systematic review and meta-analysis. J. Am. Heart Assoc. 2:e004549. doi: 10.1161/JAHA.112.004549

Gillinov, A. M., Gelijns, A. C., Parides, M. K., Derose, J. J. Jr. Moskowitz, A. J., Voisine, P., et al. (2015). Surgical ablation of atrial fibrillation during mitralvalve surgery. N. Engl. J. Med. 372, 1399-1409. doi: 10.1056/NEJMoa1500528

Goldbeter, A. (1975). Mechanism for oscillatory synthesis of cyclic AMP in Dictyostelium discoideum. Nature 253, 540-542. doi: 10.1038/253540a0

Gould, P. A., YII, M., Mclean, C., Finch, S., Marshall, T., Lambert, G. W., et al. (2006). Evidence for increased atrial sympathetic innervation in persistent human atrial fibrillation. Pacing Clin. Electrophysiol. 29, 821-829. doi: 10.1111/j.1540-8159.2006.00447.x

Grace, A., Verma, A., and Willems, S. (2017). Dipole density mapping of atrial fibrillation. Eur. Heart J. 38, 5-9. doi: 10.1093/eurheartj/ehw585

Gray, R. A., Pertsov, A. M., and Jalife, J. (1998). Spatial and temporal organization during cardiac fibrillation. Nature 392, 75-78. doi: 10.1038/32164

Gudbjartsson, D. F., Arnar, D. O., Helgadottir, A., Gretarsdottir, S., Holm, H., Sigurdsson, A., et al. (2007). Variants conferring risk of atrial fibrillation on chromosome 4q25. Nature 448, 353-357. doi: 10.1038/nature06007

Gulrajani, R. M., Savard, P., and Roberge, F. A. (1988). The inverse problem in electrocardiography: solutions in terms of equivalent sources. Crit. Rev. Biomed. Eng. 16, 171-214.

Guo, Y., Lip, G. Y., and Apostolakis, S. (2012). Inflammation in atrial fibrillation. J. Am. Coll. Cardiol. 60, 2263-2270. doi: 10.1016/j.jacc.2012.04.063

Haissaguerre, M., Hocini, M., Denis, A., Shah, A. J., Komatsu, Y., Yamashita, S., et al. (2014). Driver domains in persistent atrial fibrillation. Circulation 130, 530-538. doi: 10.1161/CIRCULATIONAHA.113.005421

Haïssaguerre, M., Hocini, M., Sanders, P., Takahashi, Y., Rotter, M., Sacher, F., et al. (2006). Localized sources maintaining atrial fibrillation organized by prior ablation. Circulation. 113, 616-625. doi: 10.1161/CIRCULATIONAHA.105.546648

Haïssaguerre, M., Jais, P., Shah, D. C., Takahashi, A., Hocini, M., Quiniou, G., et al. (1998). Spontaneous initiation of atrial fibrillation by ectopic beats originating in the pulmonary veins. N. Engl. J. Med. 339, 659-666. doi: 10.1056/NEJM199809033391003

Haissaguerre, M., Shah, A. J., Cochet, H., Hocini, M., Dubois, R., Efimov, I., et al. (2016). Intermittent drivers anchoring to structural heterogeneities as a major 
pathophysiological mechanism of human persistent atrial fibrillation. J. Physiol. 594, 2387-2398. doi: 10.1113/JP270617

Haissaguerre, M., Shah, D. C., Jais, P., Hocini, M., Yamane, T., Deisenhofer, I., et al. (2000). Electrophysiological breakthroughs from the left atrium to the pulmonary veins. Circulation 102, 2463-2465. doi: 10.1161/01.CIR.102.20.2463

Han, S., Kobayashi, K., Joung, B., Piccirillo, G., Maruyama, M., Vinters, H. V., et al. (2012). Electroanatomic remodeling of the left stellate ganglion after myocardial infarction. J. Am. Coll. Cardiol. 59, 954-961. doi: 10.1016/j.jacc.2011.11.030

Hansen, B. J., Csepe, T. A., Zhao, J., Ignozzi, A. J., Hummel, J. D., and Fedorov, V. V. (2016). Maintenance of atrial fibrillation: are reentrant drivers with spatial stability the key? Circ. Arrhythm. Electrophysiol. 9:e004398. doi: 10.1161/CIRCEP.116.004398

Hansen, B. J., Zhao, J., Csepe, T. A., Moore, B. T., Li, N., Jayne, L. A., et al. (2015). Atrial fibrillation driven by micro-anatomic intramural re-entry revealed by simultaneous sub-epicardial and sub-endocardial optical mapping in explanted human hearts. Eur. Heart J. 36, 2390-2401. doi: 10.1093/eurheartj/ehv233

Hansen, B. J., Zhao, J., and Fedorov, V. V. (2017). Fibrosis and atrial fibrillation: computerized and optical mapping; a view into the human atria at submillimeter resolution. JACC Clin. Electrophysiol. 3, 531-546. doi: $10.1016 /$ j.jacep.2017.05.002

Hatem, S. N., and Sanders, P. (2014). Epicardial adipose tissue and atrial fibrillation. Cardiovasc. Res. 102, 205-213. doi: 10.1093/cvr/cvu045

Hayward, R. M., Upadhyay, G. A., Mela, T., Ellinor, P. T., Barrett, C. D., Heist, E. K., et al. (2011). Pulmonary vein isolation with complex fractionated atrial electrogram ablation for paroxysmal and nonparoxysmal atrial fibrillation: a meta-analysis. Heart Rhythm8, 994-1000. doi: 10.1016/j.hrthm.2011.02.033

Heijman, J., Voigt, N., Nattel, S., and Dobrev, D. (2014). Cellular and molecular electrophysiology of atrial fibrillation initiation, maintenance, and progression. Circ. Res. 114, 1483-1499. doi: 10.1161/CIRCRESAHA.114.302226

Hirose, M., and Laurita, K. R. (2007). Calcium-mediated triggered activity is an underlying cellular mechanism of ectopy originating from the pulmonary vein in dogs. Am. J. Physiol. Heart Circ. Physiol. 292, H1861-H1867. doi: 10.1152/ajpheart.00826.2006

Hocini, M., Ho, S. Y., Kawara, T., Linnenbank, A. C., Potse, M., Shah, D., et al. (2002). Electrical conduction in canine pulmonary veins: electrophysiological and anatomic correlation. Circulation 105, 2442-2448. doi: 10.1161/01.CIR.0000016062.80020.11

Hocini, M., Jais, P., Sanders, P., Takahashi, Y., Rotter, M., Rostock, T., et al. (2005). Techniques, evaluation, and consequences of linear block at the left atrial roof in paroxysmal atrial fibrillation: a prospective randomized study. Circulation 112, 3688-3696. doi: 10.1161/CIRCULATIONAHA.105.541052

Hocini, M., Nault, I., Wright, M., Veenhuyzen, G., Narayan, S. M., Jaïs, P., et al. (2010). Disparate evolution of right and left atrial rate during ablation of long-lasting persistent atrial fibrillation. J. Am. Coll. Cardiol. 55, 1007-1016. doi: 10.1016/j.jacc.2009.09.060

Honarbakhsh, S., Schilling, R. J., Dhillon, G., Ullah, W., Keating, E., Providencia, R., et al. (2017). A novel mapping system for panoramic mapping of the left atrium. application to detect and characterize localized sources maintaining AF. JACC Clin. Electrophysiol. 4, 124-134. doi: 10.1016/j.jacep.2017.09.177

Huang, H., and Darbar, D. (2016). Genotype influence in responses to therapy for atrial fibrillation. Expert Rev. Cardiovasc. Ther. 14, 1119-1131. doi: $10.1080 / 14779072.2016 .1210510$

Hung, Y., Lo, L. W., Lin, Y. J., Chang, S. L., Hu, Y. F., Chung, F. P., et al. (2017). Characteristics and long-term catheter ablation outcome in long-standing persistent atrial fibrillation patients with non-pulmonary vein triggers. Int. J. Cardiol. 241, 205-211. doi: 10.1016/j.ijcard.2017.04.050

Hwang, C., and Chen, P. S. (2009). Ligament of Marshall: why it is important for atrial fibrillation ablation. Heart Rhythm. 6, S35-S40. doi: 10.1016/j.hrthm.2009.08.034

Iwasaki, Y. K., Nishida, K., Kato, T., and Nattel, S. (2011). Atrial fibrillation pathophysiology: implications for management. Circulation 124, 2264-2274. doi: 10.1161/CIRCULATIONAHA.111.019893

Jadidi, A. S., Cochet, H., Shah, A. J., Kim, S. J., Duncan, E., Miyazaki, S., et al. (2013). Inverse relationship between fractionated electrograms and atrial fibrosis in persistent atrial fibrillation: combined magnetic resonance imaging and high-density mapping. J. Am. Coll. Cardiol. 62, 802-812. doi: 10.1016/j.jacc.2013.03.081
Jadidi, A. S., Duncan, E., Miyazaki, S., Lellouche, N., Shah, A. J., Forclaz, A., et al. (2012). Functional nature of electrogram fractionation demonstrated by left atrial high density mapping. Circ. Arrhythm. Electrophysiol. 5, 32-42. doi: 10.1161/CIRCEP.111.964197

Jadidi, A. S., Lehrmann, H., Keyl, C., Sorrel, J., Markstein, V., Minners, J., et al. (2016). Ablation of Persistent Atrial Fibrillation Targeting Low-Voltage Areas With Selective Activation Characteristics. Circ. Arrhythm. Electrophysiol. 9:e002962. doi: 10.1161/CIRCEP.115.002962

Jais, P., Hocini, M., Hsu, L. F., Sanders, P., Scavee, C., Weerasooriya, R., et al. (2004). Technique and results of linear ablation at the mitral isthmus. Circulation 110, 2996-3002. doi: 10.1161/01.CIR.0000146917.75041.58

Janes, R. D., Brandys, J. C., Hopkins, D. A., Johnstone, D. E., Murphy, D. A., and Armour, J. A. (1986). Anatomy of human extrinsic cardiac nerves and ganglia. Am. J. Cardiol. 57, 299-309. doi: 10.1016/0002-9149(86) 90908-2

Jayachandran, J. V., Sih, H. J., Winkle, W., Zipes, D. P., Hutchins, G. D., and Olgin, J. E. (2000). Atrial fibrillation produced by prolonged rapid atrial pacing is associated with heterogeneous changes in atrial sympathetic innervation. Circulation 101, 1185-1191. doi: 10.1161/01.CIR.101.10.1185

Jia, P., Ramanathan, C., Ghanem, R. N., Ryu, K., Varma, N., and Rudy, Y. (2006). Electrocardiographic imaging of cardiac resynchronization therapy in heart failure: observation of variable electrophysiologic responses. Heart Rhythm. 3, 296-310. doi: 10.1016/j.hrthm.2005.11.025

John, B., Stiles, M. K., Kuklik, P., Chandy, S. T., Young, G. D., Mackenzie, L., et al. (2008). Electrical remodelling of the left and right atria due to rheumatic mitral stenosis. Eur. Heart J. 29, 2234-2243. doi: 10.1093/eurheartj/ehn329

Kalifa, J., Jalife, J., Zaitsev, A. V., Bagwe, S., Warren, M., Moreno, J., et al. (2003). Intra-atrial pressure increases rate and organization of waves emanating from the superior pulmonary veins during atrial fibrillation. Circulation 108, 668-671. doi: 10.1161/01.CIR.0000086979.39843.7B

Karam, B. S., Chavez-Moreno, A., Koh, W., Akar, J. G., and Akar, F. G. (2017). Oxidative stress and inflammation as central mediators of atrial fibrillation in obesity and diabetes. Cardiovasc. Diabetol. 16:120. doi: 10.1186/s12933-017-0604-9

Katritsis, D., Ellenbogen, K. A., Giazitzoglou, E., Sougiannis, D., Paxinos, G., Fragakis, N., et al. (2008). Clinical outcome of left atrial ablation for paroxysmal atrial fibrillation is related to the extent of radiofrequency ablation. J. Interv. Card. Electrophysiol. 22, 31-37. doi: 10.1007/s10840-008-9247-9

Katritsis, D. G., Pokushalov, E., Romanov, A., Giazitzoglou, E., Siontis, G. C., Po, S. S., et al. (2013). Autonomic denervation added to pulmonary vein isolation for paroxysmal atrial fibrillation: a randomized clinical trial. J. Am. Coll. Cardiol. 62, 2318-2325. doi: 10.1016/j.jacc.2013.06.053

Kawara, T., Derksen, R., De Groot, J. R., Coronel, R., Tasseron, S., Linnenbank, A. C., et al. (2001). Activation delay after premature stimulation in chronically diseased human myocardium relates to the architecture of interstitial fibrosis. Circulation 104, 3069-3075. doi: 10.1161/hc5001.100833

Kettering, K., Yim, D. H., and Gramley, F. (2017). Catheter ablation of persistent atrial fibrillation: circumferential pulmonary vein ablation: beneficial effect of an additional linear lesion at the roof of the left atrium on the long-term outcome. Herzschrittmacherther. Elektrophysiol. 28, 328-334. doi: 10.1007/s00399-017-0519-x

Khurram, I. M., Habibi, M., Gucuk Ipek, E., Chrispin, J., Yang, E., Fukumoto, K., et al. (2016). Left atrial LGE and arrhythmia recurrence following pulmonary vein isolation for paroxysmal and persistent AF. JACC Cardiovasc. Imaging 9, 142-148. doi: 10.1016/j.jcmg.2015.10.015

Kim, T. H., Park, J., Park, J. K., Uhm, J. S., Joung, B., Hwang, C., et al. (2015). Linear ablation in addition to circumferential pulmonary vein isolation (Dallas lesion set) does not improve clinical outcome in patients with paroxysmal atrial fibrillation: a prospective randomized study. Europace 17, 388-395. doi: 10.1093/europace/euu245

Kis, Z., Muka, T., Franco, O. H., Bramer, W. M., De Vries, L. J., Kardos, A., et al. (2017). The short and long-term efficacy of pulmonary vein isolation as a sole treatment strategy for paroxysmal atrial fibrillation: a systematic review and meta-analysis. Curr. Cardiol. Rev. 13, 199-208. doi: 10.2174/1573403X13666170117125124

Kistler, P. M., Sanders, P., Dodic, M., Spence, S. J., Samuel, C. S., Zhao, C., et al. (2006). Atrial electrical and structural abnormalities in an ovine model of chronic blood pressure elevation after prenatal corticosteroid exposure: 
implications for development of atrial fibrillation. Eur. Heart J. 27, 3045-3056. doi: 10.1093/eurheartj/ehl360

Knecht, S., Sohal, M., Deisenhofer, I., Albenque, J. P., Arentz, T., Neumann, T., et al. (2017). Multicentre evaluation of non-invasive biatrial mapping for persistent atrial fibrillation ablation: the AFACART study. Europace 19, 1302-1309. doi: 10.1093/europace/euw168

Konings, K. T., Kirchhof, C. J., Smeets, J. R., Wellens, H. J., Penn, O. C., and Allessie, M. A. (1994). High-density mapping of electrically induced atrial fibrillation in humans. Circulation 89, 1665-1680. doi: 10.1161/01.CIR.89.4.1665

Konings, K. T., Smeets, J. L., Penn, O. C., Wellens, H. J., and Allessie, M. A. (1997). Configuration of unipolar atrial electrograms during electrically induced atrial fibrillation in humans. Circulation 95, 1231-1241. doi: 10.1161/01.CIR.95.5.1231

Krul, S. P. J., Driessen, A. H. G., Van Boven, W. J., Linnenbank, A. C., Geuzebroek, G. S. C., Jackman, W. M., et al. (2011). Thoracoscopic videoassisted pulmonary vein antrum isolation, ganglionated plexus ablation, and periprocedural confirmation of ablation lesions: first results of a hybrid surgical-electrophysiological approach for atrial fibrillation. Circ. Arrhythm. Electrophysiol. 4, 262-270. doi: 10.1161/CIRCEP.111.961862

Kuck, K. H., Brugada, J., Furnkranz, A., Metzner, A., Ouyang, F., Chun, K. R., et al. (2016a). Cryoballoon or radiofrequency ablation for paroxysmal atrial fibrillation. N. Engl. J. Med. 374, 2235-2245. doi: 10.1056/NEJMoa1602014

Kuck, K. H., Hoffmann, B. A., Ernst, S., Wegscheider, K., Treszl, A., Metzner, A., et al. (2016b). Impact of complete versus incomplete circumferential lines around the pulmonary veins during catheter ablation of paroxysmal atrial fibrillation: results from the gap-atrial fibrillation-german atrial fibrillation competence network 1 trial. Circ. Arrhythm. Electrophysiol. 9:e003337. doi: 10.1161/CIRCEP.115.003337

Kurfirst, V., Mokráček, A., Bulava, A., Canádyov,á, J., Hani,š, J., and Pešl, L. (2014). Two-staged hybrid treatment of persistent atrial fibrillation: shortterm single-centre results ${ }^{\dagger}$. Interact. Cardiovasc. Thorac. Surg. 18, 451-456. doi: 10.1093 /icvts/ivt538

La Meir, M., Gelsomino, S., Luc,à, F., Pison, L., Parise, O., Colella, A., et al. (2013). Minimally invasive surgical treatment of lone atrial fibrillation: early results of hybrid versus standard minimally invasive approach employing radiofrequency sources. Int. J. Cardiol. 167, 1469-1475. doi: 10.1016/j.ijcard.2012. 04.044

Lau, D. H., Mackenzie, L., Kelly, D. J., Psaltis, P. J., Brooks, A. G., Worthington, M., et al.(2010a). Hypertension and atrial fibrillation: evidence of progressive atrial remodeling with electrostructural correlate in a conscious chronically instrumented ovine model. Heart Rhythm. 7, 1282-1290. doi: 10.1016/j.hrthm.2010.05.010

Lau, D. H., Mackenzie, L., Kelly, D. J., Psaltis, P. J., Worthington, M., Rajendram, A., et al. (2010b). Short-term hypertension is associated with the development of atrial fibrillation substrate: a study in an ovine hypertensive model. Heart Rhythm 7, 396-404. doi: 10.1016/j.hrthm.2009.11.031

Lau, D. H., Maesen, B., Zeemering, S., Kuklik, P., Van Hunnik, A., Lankveld, T. A., et al. (2015). Indices of bipolar complex fractionated atrial electrograms correlate poorly with each other and atrial fibrillation substrate complexity. Heart Rhythm 12, 1415-1423. doi: 10.1016/j.hrthm.2015.03.017

Lau, D. H., Psaltis, P. J., Mackenzie, L., Kelly, D. J., Carbone, A., Worthington, M., et al. (2011). Atrial remodeling in an ovine model of anthracyclineinduced nonischemic cardiomyopathy: remodeling of the same sort. $J$. Cardiovasc. Electrophysiol. 22, 175-182. doi: 10.1111/j.1540-8167.2010. 01851.x

Lau, D. H., Shipp, N. J., Kelly, D. J., Thanigaimani, S., Neo, M., Kuklik, P., et al. (2013). Atrial arrhythmia in ageing spontaneously hypertensive rats: unraveling the substrate in hypertension and ageing. PLOS ONE 8:e72416. doi: 10.1371/journal.pone.0072416

Laughner, J., Shome, S., Child, N., Shuros, A., Neuzil, P., Gill, J., et al. (2016). Practical considerations of mapping persistent atrial fibrillation with whole-chamber basket catheters. JACC Clin. Electrophysiol. 2, 55-65. doi: 10.1016/j.jacep.2015.09.017

Lechleiter, J., Girard, S., Peralta, E., and Clapham, D. (1991). Spiral calcium wave propagation and annihilation in Xenopus laevis oocytes. Science 252, 123-126. doi: $10.1126 /$ science. 2011747
Lee, J. Y., Kim, T. H., Yang, P. S., Lim, H. E., Choi, E. K., Shim, J., et al. (2017) Korean atrial fibrillation network genome-wide association study for earlyonset atrial fibrillation identifies novel susceptibility loci. Eur. Heart J. 38, 2586-2594. doi: 10.1093/eurheartj/ehx213

Lee, S. H., Tai, C. T., Hsieh, M. H., Tsao, H. M., Lin, Y. J., Chang, S. L., et al. (2005). Predictors of non-pulmonary vein ectopic beats initiating paroxysmal atrial fibrillation: implication for catheter ablation. J. Am. Coll. Cardiol. 46, 1054-1059. doi: 10.1016/j.jacc.2005.06.016

Leiria, T. L., Glavinovic, T., Armour, J. A., Cardinal, R., De Lima, G. G., and Kus, T. (2011). Longterm effects of cardiac mediastinal nerve cryoablation on neural inducibility of atrial fibrillation in canines. Auton. Neurosci. 161, 68-74. doi: 10.1016/j.autneu.2010.12.006

Lemoine, M. D., Duverger, J. E., Naud, P., Chartier, D., Qi, X. Y., Comtois, P., et al. (2011). Arrhythmogenic left atrial cellular electrophysiology in a murine genetic long QT syndrome model. Cardiovasc. Res. 92, 67-74. doi: $10.1093 / \mathrm{cvr} / \mathrm{cvr} 166$

Leone, O., Boriani, G., Chiappini, B., Pacini, D., Cenacchi, G., Martin Suarez, S., et al. (2004). Amyloid deposition as a cause of atrial remodelling in persistent valvular atrial fibrillation. Eur. Heart J. 25, 1237-1241. doi: 10.1016/j.ehj.2004.04.007

Li, D., Fareh, S., Leung, T. K., and Nattel, S. (1999). Promotion of atrial fibrillation by heart failure in dogs: atrial remodeling of a different sort. Circulation 100, 87-95. doi: 10.1161/01.CIR.100.1.87

Lim, H. S., Hocini, M., Dubois, R., Denis, A., Derval, N., Zellerhoff, S., et al. (2017). Complexity and distribution of drivers in relation to duration of persistent atrial fibrillation. J. Am. Coll. Cardiol. 69, 1257-1269. doi: 10.1016/j.jacc.2017.01.014

Lin, W. S., Tai, C. T., Hsieh, M. H., Tsai, C. F., Lin, Y. K., Tsao, H. M., et al. (2003). Catheter ablation of paroxysmal atrial fibrillation initiated by non-pulmonary vein ectopy. Circulation 107, 3176-3183. doi: 10.1161/01.CIR.0000074206.52056.2D

Linz, D., Hohl, M., Dhein, S., Ruf, S., Reil, J. C., Kabiri, M., et al. (2016). Cathepsin A mediates susceptibility to atrial tachyarrhythmia and impairment of atrial emptying function in Zucker diabetic fatty rats. Cardiovasc. Res. 110, 371-380. doi: $10.1093 / \mathrm{cvr} / \mathrm{cvw} 071$

Lo, L. W., Tai, C. T., Lin, Y. J., Chang, S. L., Wongcharoen, W., Hsieh, M. H. et al. (2007). Mechanisms of recurrent atrial fibrillation: comparisons between segmental ostial versus circumferential pulmonary vein isolation. J. Cardiovasc. Electrophysiol. 18, 803-807. doi: 10.1111/j.1540-8167.2007.00848.x

Low, S. K., Takahashi, A., Ebana, Y., Ozaki, K., Christophersen, I. E., Ellinor, P. T., et al. (2017). Identification of six new genetic loci associated with atrial fibrillation in the Japanese population. Nat. Genet. 49, 953-958. doi: $10.1038 /$ ng. 3842

Lu, Z., Scherlag, B. J., Lin, J., Yu, L., Guo, J. H., Niu, G., et al. (2009). Autonomic mechanism for initiation of rapid firing from atria and pulmonary veins: evidence by ablation of ganglionated plexi. Cardiovasc. Res. 84, 245-252. doi: 10.1093/cvr/cvp194

Lubitz, S. A., Lunetta, K. L., Lin, H., Arking, D. E., Trompet, S., Li, G., et al. (2014). Novel genetic markers associate with atrial fibrillation risk in Europeans and Japanese. J. Am. Coll. Cardiol. 63, 1200-1210. doi: 10.1016/j.jacc.2013.12.015

Lubitz, S. A., Yin, X., Fontes, J. D., Magnani, J. W., Rienstra, M., Pai, M., et al. (2010). Association between familial atrial fibrillation and risk of new-onset atrial fibrillation. JAMA 304, 2263-2269. doi: 10.1001/jama.2010.1690

Mahida, S., Sacher, F., Derval, N., Berte, B., Yamashita, S., Hooks, D., et al. (2015). Science linking pulmonary veins and atrial fibrillation. Arrhythm Electrophysiol Rev. 4, 40-43. doi: 10.15420/aer.2015.4.1.40

Malcolme-Lawes, L. C., Juli, C., Karim, R., Bai, W., Quest, R., Lim, P. B., et al. (2013). Automated analysis of atrial late gadolinium enhancement imaging that correlates with endocardial voltage and clinical outcomes: a 2-center study. Heart Rhythm. 10, 1184-1191. doi: 10.1016/j.hrthm.2013.04.030

Mandapati, R., Skanes, A., Chen, J., Berenfeld, O., and Jalife, J. (2000). Stable microreentrant sources as a mechanism of atrial fibrillation in the isolated sheep heart. Circulation 101, 194-199. doi: 10.1161/01.CIR.101.2.194

Mansour, M., Mandapati, R., Berenfeld, O., Chen, J., Samie, F. H., and Jalife, J. (2001). Left-to-right gradient of atrial frequencies during acute atrial fibrillation in the isolated sheep heart. Circulation 103, 2631-2636. doi: 10.1161/01.CIR.103.21.2631 
Mansour, M., Ruskin, J., and Keane, D. (2002). Initiation of atrial fibrillation by ectopic beats originating from the ostium of the inferior vena cava. J. Cardiovasc. Electrophysiol. 13, 1292-1295. doi: 10.1046/j.1540-8167.2002.01292.x

Marrouche, N. F., Brachmann, J., Andresen, D., Siebels, J., Boersma, L., Jordaens, L., et al. (2018). Catheter ablation for atrial fibrillation with heart failure. $N$. Engl. J. Med. 378, 417-427. doi: 10.1056/NEJMoa1707855

Marrouche, N. F., Wilber, D., Hindricks, G., Jais, P., Akoum, N., Marchlinski, F., et al. (2014). Association of atrial tissue fibrosis identified by delayed enhancement MRI and atrial fibrillation catheter ablation: the DECAAF study. JAMA 311, 498-506. doi: 10.1001/jama.2014.3

Medi, C., Kalman, J. M., Ling, L. H., Teh, A. W., Lee, G., Lee, G., et al. (2012). Atrial electrical and structural remodeling associated with longstanding pulmonary hypertension and right ventricular hypertrophy in humans. J. Cardiovasc. Electrophysiol. 23, 614-620. doi: 10.1111/j.1540-8167.2011.02255.x

Medi, C., Kalman, J. M., Spence, S. J., Teh, A. W., Lee, G., Bader, I., et al. (2011). Atrial electrical and structural changes associated with longstanding hypertension in humans: implications for the substrate for atrial fibrillation. J. Cardiovasc. Electrophysiol. 22, 1317-1324. doi: 10.1111/j.1540-8167.2011.02125.x

Metzner, A., Wissner, E., Tsyganov, A., Kalinin, V., Schluter, M., Lemes, C., et al. (2017). Noninvasive phase mapping of persistent atrial fibrillation in humans: Comparison with invasive catheter mapping. Ann Noninvasive Electrocardiol. 23:e12527. doi: 10.1111/anec.12527

Mikhaylov, E., Kanidieva, A., Sviridova, N., Abramov, M., Gureev, S., Szili-Torok, T., et al. (2011). Outcome of anatomic ganglionated plexi ablation to treat paroxysmal atrial fibrillation: a 3-year follow-up study. Europace 13, 362-370. doi: 10.1093/europace/euq416

Mitchell, A. R., Spurrell, P. A., and Sulke, N. (2003). Circadian variation of arrhythmia onset patterns in patients with persistent atrial fibrillation. Am. Heart J. 146, 902-907. doi: 10.1016/S0002-8703(03)00405-8

Miyasaka, Y., Barnes, M. E., Bailey, K. R., Cha, S. S., Gersh, B. J., Seward, J. B., et al. (2007). Mortality trends in patients diagnosed with first atrial fibrillation: a 21-year community-based study. J. Am. Coll. Cardiol. 49, 986-992. doi: 10.1016/j.jacc.2006.10.062

Moe, G. K., Rheinboldt, W. C., and Abildskov, J. A. (1964). A computer model of atrial fibrillation. Am. Heart J. 67, 200-220. doi: 10.1016/0002-8703(64)90371-0

Morgan, R., Colman, M. A., Chubb, H., Seemann, G., and Aslanidi, O. V. (2016). Slow conduction in the border zones of patchy fibrosis stabilizes the drivers for atrial fibrillation: insights from multi-scale human atrial modeling. Front. Physiol. 7:474. doi: 10.3389/fphys.2016.00474

Mun, H. S., Joung, B., Shim, J., Hwang, H. J., Kim, J. Y., Lee, M. H., et al. (2012). Does additional linear ablation after circumferential pulmonary vein isolation improve clinical outcome in patients with paroxysmal atrial fibrillation? Prospective randomised study. Heart 98, 480-484. doi: 10.1136/heartjnl-2011-301107

Nademanee, K., Mckenzie, J., Kosar, E., Schwab, M., Sunsaneewitayakul, B., Vasavakul, T., et al. (2004). A new approach for catheter ablation of atrial fibrillation: mapping of the electrophysiologic substrate. J. Am. Coll. Cardiol. 43, 2044-2053. doi: 10.1016/j.jacc.2003.12.054

Namino, F., Iriki, Y., Maenosono, R., Ichiki, H., Okui, H., Yoshimura, A., et al. (2015). The optimal setting of complex fractionated atrial electrogram software in substrate ablation for atrial fibrillation. J Arrhythm. 31, 6-11. doi: 10.1016/j.joa.2014.04.006

Narayan, S. M., Krummen, D. E., and Rappel, W. J. (2012a). Clinical mapping approach to diagnose electrical rotors and focal impulse sources for human atrial fibrillation. J. Cardiovasc. Electrophysiol. 23, 447-454. doi: 10.1111/j.1540-8167.2012.02332.x

Narayan, S. M., Krummen, D. E., Shivkumar, K., Clopton, P., Rappel, W. J., and Miller, J. M. (2012b). Treatment of atrial fibrillation by the ablation of localized sources: CONFIRM (Conventional Ablation for Atrial Fibrillation With or Without Focal Impulse and Rotor Modulation) trial. J. Am. Coll. Cardiol. 60, 628-636. doi: 10.1016/j.jacc.2012.05.022

Natale, A., Reddy, V. Y., Monir, G., Wilber, D. J., Lindsay, B. D., Mcelderry, H. T., et al. (2014). Paroxysmal AF catheter ablation with a contact force sensing catheter: results of the prospective, multicenter SMART-AF trial. J. Am. Coll. Cardiol. 64, 647-656. doi: 10.1016/j.jacc.2014.04.072
Nattel, S. (2002). New ideas about atrial fibrillation 50 years on. Nature 415, 219-226. doi: 10.1038/415219a

Nattel, S., and Dobrev, D. (2016). Electrophysiological and molecular mechanisms of paroxysmal atrial fibrillation. Nat. Rev. Cardiol. 13, 575-590. doi: $10.1038 /$ nrcardio. 2016.118

Nattel, S., and Harada, M. (2014). Atrial remodeling and atrial fibrillation: recent advances and translational perspectives. J. Am. Coll. Cardiol. 63, 2335-2345. doi: 10.1016/j.jacc.2014.02.555

Nattel, S., Xiong, F., and Aguilar, M. (2017). Demystifying rotors and their place in clinical translation of atrial fibrillation mechanisms. Nat. Rev. Cardiol. 14, 509-520. doi: 10.1038/nrcardio.2017.37

Neumann, T., Wojcik, M., Berkowitsch, A., Erkapic, D., Zaltsberg, S., Greiss, H., et al. (2013). Cryoballoon ablation of paroxysmal atrial fibrillation: 5year outcome after single procedure and predictors of success. Europace 15, 1143-1149. doi: 10.1093/europace/eut021

Ng, J., Villuendas, R., Cokic, I., Schliamser, J. E., Gordon, D., Koduri, H., et al. (2011). Autonomic remodeling in the left atrium and pulmonary veins in heart failure - creation of a dynamic substrate for atrial fibrillation. Circ. Arrhythm. Electrophysiol. 4, 388-396. doi: 10.1161/CIRCEP.110.959650

Nguyen, B. L., Fishbein, M. C., Chen, L. S., Chen, P.-S., and Masroor, S. (2009). Histopathological substrate for chronic atrial fibrillation in humans. Heart Rhythm6, 454-460. doi: 10.1016/j.hrthm.2009.01.010

Nguyen, B. L., Li, H., Fishbein, M. C., Lin, S. F., Gaudio, C., Chen, P. S., et al. (2012). Acute myocardial infarction induces bilateral stellate ganglia neural remodeling in rabbits. Cardiovasc. Pathol. 21, 143-148. doi: 10.1016/j.carpath.2011.08.001

Nielsen, J. B., Fritsche, L. G., Zhou, W., Teslovich, T. M., Holmen, O. L., Gustafsson, S., et al. (2018a). Genome-wide study of atrial fibrillation identifies seven risk loci and highlights biological pathways and regulatory elements involved in cardiac development. Am. J. Hum. Genet. 102, 103-115. doi: 10.1016/j.ajhg.2017.12.003

Nielsen, J. B., Thorolfsdottir, R. B., Fritsche, L. G., Zhou, W., Skov, M. W., Graham, S. E., et al. (2018b). Biobank-driven genomic discovery yields new insight into atrial fibrillation biology. Nat. Genet. 50, 1234-1239. doi: 10.1038/s41588-018-0171-3

Oakes, R. S., Badger, T. J., Kholmovski, E. G., Akoum, N., Burgon, N. S., Fish, E. N., et al. (2009). Detection and quantification of left atrial structural remodeling using delayed enhancement MRI in patients with atrial fibrillation. Circulation 119, 1758-1767. doi: 10.1161/CIRCULATIONAHA.108.811877

Oesterlein, T., Frisch, D., Loewe, A., Seemann, G., Schmitt, C., Dössel, O., et al. (2016). Basket-type catheters: diagnostic pitfalls caused by deformation and limited coverage. Biomed Res. Int. 2016:13. doi: 10.1155/2016/5340574

Ogawa, M., Tan, A. Y., Song, J., Kobayashi, K., Fishbein, M. C., Lin, S. F., et al. (2009). Cryoablation of stellate ganglia and atrial arrhythmia in ambulatory dogs with pacing-induced heart failure. Heart Rhythm. 6, 1772-1779. doi: 10.1016/j.hrthm.2009.08.011

Oral, H., Chugh, A., Good, E., Wimmer, A., Dey, S., Gadeela, N., et al. (2007). Radiofrequency catheter ablation of chronic atrial fibrillation guided by complex electrograms. Circulation 115, 2606-2612. doi: 10.1161/CIRCULATIONAHA.107.691386

Oral, H., Chugh, A., Yoshida, K., Sarrazin, J. F., Kuhne, M., Crawford, T., et al. (2009). A randomized assessment of the incremental role of ablation of complex fractionated atrial electrograms after antral pulmonary vein isolation for long-lasting persistent atrial fibrillation. J. Am. Coll. Cardiol. 53, 782-789. doi: 10.1016/j.jacc.2008.10.054

Oster, H. S., Taccardi, B., Lux, R. L., Ershler, P. R., and Rudy, Y. (1997). Noninvasive electrocardiographic imaging. Reconstruction of epicardial potentials, electrograms, and isochrones and localization of single and multiple electrocardiac events. Circulation 96, 1012-1024.

Oyen, N., Ranthe, M. F., Carstensen, L., Boyd, H. A., Olesen, M. S., Olesen, S. P., et al. (2012). Familial aggregation of lone atrial fibrillation in young persons. J. Am. Coll. Cardiol. 60, 917-921. doi: 10.1016/j.jacc.2012.03.046

Pandey, A., Kim, S., Moore, C., Thomas, L., Gersh, B., Allen, L. A., et al. (2017). Predictors and prognostic implications of incident heart failure in patients with prevalent atrial fibrillation. JACC Heart Fail. 5, 44-52. doi: 10.1016/j.jchf.2016.09.016

Pandit, S. V., and Jalife, J. (2013). Rotors and the dynamics of cardiac fibrillation. Circ. Res. 112, 849-862. doi: 10.1161/CIRCRESAHA.111.300158 
Panfilov, A. V., and Keener, J. P. (1993). Effects of high frequency stimulation on cardiac tissue with an inexcitable obstacle. J. Theor. Biol. 163, 439-448. doi: 10.1006/jtbi.1993.1129

Pappone, C., Ciconte, G., Vicedomini, G., Mangual, J. O., Li, W., Conti, M., et al. (2018). Clinical outcome of electrophysiologically guided ablation for nonparoxysmal atrial fibrillation using a novel real-time 3-dimensional mapping technique: results from a prospective randomized trial. Circ. Arrhythm. Electrophysiol. 11:e005904. doi: 10.1161/CIRCEP.117.005904

Pappone, C., Santinelli, V., Manguso, F., Vicedomini, G., Gugliotta, F., Augello, G., et al. (2004). Pulmonary vein denervation enhances long-term benefit after circumferential ablation for paroxysmal atrial fibrillation. Circulation 109, 327-334. doi: 10.1161/01.CIR.0000112641.16340.C7

Parameswaran, R., Voskoboinik, A., Gorelik, A., Lee, G., Kistler, P. M., Sanders, P., et al. (2018). Clinical impact of rotor ablation in atrial fibrillation: a systematic review. Europace Clinical impact of rotor ablation in atrial fibrillation: a systematic review. 20, 1099-1106. doi: 10.1093/europace/eux370

Parvez, B., Vaglio, J., Rowan, S., Muhammad, R., Kucera, G., Stubblefield, T., et al. (2012). Symptomatic response to antiarrhythmic drug therapy is modulated by a common single nucleotide polymorphism in atrial fibrillation. J. Am. Coll. Cardiol. 60, 539-545. doi: 10.1016/j.jacc.2012.01.070

Pastor, A., Nunez, A., Magalhaes, A., Awamleh, P., and Garcia-Cosio, F. (2007). [The superior vena cava as a site of ectopic foci in atrial fibrillation]. Rev. Esp. Cardiol. 60, 68-71. doi: 10.1016/S0300-8932(07)74987-4

Pathik, B., Kalman, J. M., Walters, T., Kuklik, P., Zhao, J., Madry, A., et al. (2018). Absence of rotational activity detected using 2-dimensional phase mapping in the corresponding 3-dimensional phase maps in human persistent atrial fibrillation. Heart Rhythm 15, 182-192. doi: 10.1016/j.hrthm.2017.09.010

Patterson, E., Po, S. S., Scherlag, B. J., and Lazzara, R. (2005). Triggered firing in pulmonary veins initiated by $<\mathrm{em}>$ in vitro $</ \mathrm{em}>$ autonomic nerve stimulation. Heart Rhythm 2, 624-631. doi: 10.1016/j.hrthm.2005.02.012

Pedersen, O. D., Abildstrom, S. Z., Ottesen, M. M., Rask-Madsen, C., Bagger, H., Kober, L., et al. (2006). Increased risk of sudden and non-sudden cardiovascular death in patients with atrial fibrillation/flutter following acute myocardial infarction. Eur. Heart J. 27, 290-295. doi: 10.1093/eurheartj/ehi629

Pertsov, A. M., Davidenko, J. M., Salomonsz, R., Baxter, W. T., and Jalife, J. (1993a). Spiral waves of excitation underlie reentrant activity in isolated cardiac muscle. Circ. Res. 72:631. doi: 10.1161/01.RES.72.3.631

Pertsov, A. M., Davidenko, J. M., Salomonsz, R., Baxter, W. T., and Jalife, J. (1993b). Spiral waves of excitation underlie reentrant activity in isolated cardiac muscle. Circ. Res. 72, 631-650.

Peters, D. C., Wylie, J. V., Hauser, T. H., Nezafat, R., Han, Y., Woo, J. J., et al. (2009). Recurrence of atrial fibrillation correlates with extent of post-procedural late gadolinium enhancement: a pilot study. JACC Cardiovasc. Imaging 2, 308-316. doi: 10.1016/j.jcmg.2008.10.016

Pison, L., Gelsomino, S., Luc,à, F., Parise, O., Maessen, J. G., Crijns, H. J. G. M., et al. (2014). Effectiveness and safety of simultaneous hybrid thoracoscopic and endocardial catheter ablation of lone atrial fibrillation. Ann. Cardiothor. Surg. 3, 38-44. doi: 10.3978/j.issn.2225-319X.2013.12.10

Pison, L., La Meir, M., Van Opstal, J., Blaauw, Y., Maessen, J., and Crijns, H. J. (2012). Hybrid thoracoscopic surgical and transvenous catheter ablation of atrial fibrillation. J. Am. Coll. Cardiol. 60, 54-61. doi: 10.1016/j.jacc.2011.12.055

Platonov, P. G., Mitrofanova, L. B., Orshanskaya, V., and Ho, S. Y. (2011). Structural abnormalities in atrial walls are associated with presence and persistency of atrial fibrillation but not with age. J. Am. Coll. Cardiol. 58, 2225-2232. doi: 10.1016/j.jacc.2011.05.061

Po, S. S., Nakagawa, H., and Jackman, W. M. (2009). Localization of left atrial ganglionated plexi in patients with atrial fibrillation. J. Cardiovasc. Electrophysiol. 20, 1186-1189. doi: 10.1111/j.1540-8167.2009.01515.x

Pokushalov, E., Romanov, A., Katritsis, D. G., Artyomenko, S., Shirokova, N., Karaskov, A., et al. (2013). Ganglionated plexus ablation vs. linear ablation in patients undergoing pulmonary vein isolation for persistent/long-standing persistent atrial fibrillation: a randomized comparison. Heart Rhythm 10, 1280-1286. doi: 10.1016/j.hrthm.2013.04.016

Potpara, T. S., Polovina, M. M., Licina, M. M., Marinkovic, J. M., and Lip, G. Y. (2013). Predictors and prognostic implications of incident heart failure following the first diagnosis of atrial fibrillation in patients with structurally normal hearts: the belgrade atrial fibrillation study. Eur. J. Heart Fail. 15, 415-424. doi: 10.1093/eurjhf/hft004
Prasad, S. M., Maniar, H. S., Camillo, C. J., Schuessler, R. B., Boineau, J. P., Sundt, T. M. III, et al. (2003). The Cox maze III procedure for atrial fibrillation: long-term efficacy in patients undergoing lone versus concomitant procedures. J. Thorac. Cardiovasc. Surg. 126, 1822-1828. doi: 10.1016/S0022-5223(03)01287-X

Ramanathan, C., Ghanem, R. N., Jia, P., Ryu, K., and Rudy, Y. (2004). Noninvasive electrocardiographic imaging for cardiac electrophysiology and arrhythmia. Nat. Med. 10, 422-428. doi: 10.1038/nm1011

Ramanathan, C., Jia, P., Ghanem, R., Calvetti, D., and Rudy, Y. (2003). Noninvasive electrocardiographic imaging (ECGI): application of the generalized minimal residual (GMRes) method. Ann. Biomed. Eng. 31, 981-994. doi: 10.1114/1.1588655

Reddy, Y. N. V., Obokata, M., Gersh, B. J., and Borlaug, B. A. (2018) High prevalence of occult heart failure with preserved ejection fraction among patients with atrial fibrillation and dyspnea. Circulation 137, 534-535. doi: 10.1161/CIRCULATIONAHA.117.030093

Redfearn, D. P., Skanes, A. C., Gula, L. J., Griffith, M. J., Marshall, H. J., Stafford, P. J., et al. (2007). Noninvasive assessment of atrial substrate change after wide area circumferential ablation: a comparison with segmental pulmonary vein isolation. Ann. Noninvasive Electrocardiol. 12, 329-337. doi: 10.1111/j.1542-474X.2007.00182.x

Reumann, M., Bohnert, J., Osswald, B., Hagl, S., and Doessel, O. (2007). Multiple wavelets, rotors, and snakes in atrial fibrillation-a computer simulation study. J. Electrocardiol. 40, 328-334. doi: 10.1016/j.jelectrocard.2006.12.016

Richer, L.-P., Vinet, A., Kus, T., Cardinal, R., Ardell, J. L., and Armour, J. A. (2008), $\alpha$-Adrenoceptor blockade modifies neurally induced atrial arrhythmias. Am. J. Physiol. 295, R1175-R1180. doi: 10.1152/ajpregu.00840.2007

Roberts, J. D., and Gollob, M. H. (2010). Impact of genetic discoveries on the classification of lone atrial fibrillation. J. Am. Coll. Cardiol. 55, 705-712. doi: 10.1016/j.jacc.2009.12.005

Roberts, J. D., and Gollob, M. H. (2014). A contemporary review on the genetic basis of atrial fibrillation. Method Debakey Cardiovasc. J. 10, 18-24. doi: $10.14797 / \mathrm{mdcj}-10-1-18$

Roberts-Thomson, K. C., John, B., Worthley, S. G., Brooks, A. G., Stiles, M. K., Lau, D. H., et al. (2009). Left atrial remodeling in patients with atrial septal defects. Heart Rhythm 6, 1000-1006. doi: 10.1016/j.hrthm.2009.03.050

Rocken, C., Peters, B., Juenemann, G., Saeger, W., Klein, H. U., Huth, C., et al. (2002). Atrial amyloidosis: an arrhythmogenic substrate for persistent atrial fibrillation. Circulation 106, 2091-2097. doi: 10.1161/01.CIR.0000034511.06350.DF

Roney, C. H., Bayer, J. D., Zahid, S., Meo, M., Boyle, P. M., Trayanova, N. A., et al. (2016). Modelling methodology of atrial fibrosis affects rotor dynamics and electrograms. Europace 18, iv146-iv155. doi: 10.1093/europace/euw365

Roney, C. H., Cantwell, C. D., Bayer, J. D., Qureshi, N. A., Lim, P. B., Tweedy, J. H., et al. (2017). Spatial resolution requirements for accurate identification of drivers of atrial fibrillation. Circ. Arrhythm. Electrophysiol. 10:e004899. doi: 10.1161/CIRCEP.116.004899

Roselli, C., Chaffin, M. D., Weng, L. C., Aeschbacher, S., Ahlberg, G., Albert, C. M., et al. (2018). Multi-ethnic genome-wide association study for atrial fibrillation. Nat. Genet. 50, 1225-1233. doi: 10.1038/s41588-018-0133-9

Rostamian, A., Narayan, S. M., Thomson, L., Fishbein, M., and Siegel, R. J. (2014). The incidence, diagnosis, and management of pulmonary vein stenosis as a complication of atrial fibrillation ablation. J. Interv. Card. Electrophysiol. 40, 63-74. doi: 10.1007/s10840-014-9885-Z

Rostock, T., Rotter, M., Sanders, P., Takahashi, Y., Jais, P., Hocini, M., et al. (2006). High-density activation mapping of fractionated electrograms in the atria of patients with paroxysmal atrial fibrillation. Heart Rhythm 3, 27-34. doi: 10.1016/j.hrthm.2005.09.019

Rostock, T., Steven, D., Lutomsky, B., Servatius, H., Drewitz, I., Klemm, H., et al. (2008). Atrial fibrillation begets atrial fibrillation in the pulmonary veins. on the impact of atrial fibrillation on the electrophysiological properties of the pulmonary veins in humans. J Am Coll Cardiol. 51, 2153-2160. doi: 10.1016/j.jacc.2008.02.059

Rudy, Y. (2013). Noninvasive electrocardiographic imaging of arrhythmogenic substrates in humans. Circ. Res. 112, 863-874. doi: 10.1161/CIRCRESAHA.112.279315

Rudy, Y., and Messinger-Rapport, B. J. (1988). The inverse problem in electrocardiography: solutions in terms of epicardial potentials. Crit. Rev. Biomed. Eng. 16, 215-268. 
Rudy, Y., and Oster, H. S. (1992). The electrocardiographic inverse problem. Crit. Rev. Biomed. Eng. 20, 25-45.

Ruigomez, A., Johansson, S., Wallander, M. A., Edvardsson, N., and Garcia Rodriguez, L. A. (2009). Risk of cardiovascular and cerebrovascular events after atrial fibrillation diagnosis. Int. J. Cardiol. 136, 186-192. doi: 10.1016/j.ijcard.2008.04.050

Ruigomez, A., Johansson, S., Wallander, M. A., and Garcia Rodriguez, L. A. (2002). Risk of mortality in a cohort of patients newly diagnosed with chronic atrial fibrillation. BMC Cardiovasc. Disord. 2:5. doi: 10.1186/1471-2261-2-5

Sampson, K. J., and Henriquez, C. S. (2002). Interplay of ionic and structural heterogeneity on functional action potential duration gradients: implications for arrhythmogenesis. Chaos 12, 819-828. doi: 10.1063/1.1497735

Sanders, P., Morton, J. B., Davidson, N. C., Spence, S. J., Vohra, J. K., Sparks, P. B., et al. (2003). Electrical remodeling of the atria in congestive heart failure: electrophysiological and electroanatomic mapping in humans. Circulation 108, 1461-1468. doi: 10.1161/01.CIR.0000090688.49283.67

Sanders, P., Morton, J. B., Deen, V. R., Davidson, N. C., Sparks, P. B., Vohra, J. K., et al. (2002). Immediate and long-term results of radiofrequency ablation of pulmonary vein ectopy for cure of paroxysmal atrial fibrillation using a focal approach. Intern. Med. J. 32, 202-207. doi: 10.1046/j.1445-5994.2002.00215.x

Scanavacca, M., Pisani, C. F., Hachul, D., Lara, S., Hardy, C., Darrieux, F., et al. (2006). Selective atrial vagal denervation guided by evoked vagal reflex to treat patients with paroxysmal atrial fibrillation. Circulation 114, 876-885. doi: 10.1161/CIRCULATIONAHA.106.633560

Scherr, D., Dalal, D., Cheema, A., Cheng, A., Henrikson, C. A., Spragg, D., et al. (2007). Automated detection and characterization of complex fractionated atrial electrograms in human left atrium during atrial fibrillation. Heart Rhythm 4, 1013-1020. doi: 10.1016/j.hrthm.2007.04.021

Schotten, U., Verheule, S., Kirchhof, P., and Goette, A. (2011). Pathophysiological mechanisms of atrial fibrillation: a translational appraisal. Physiol. Rev. 91, 265-325. doi: 10.1152/physrev.00031.2009

Schreiber, D., Rieger, A., Moser, F., and Kottkamp, H. (2017). Catheter ablation of atrial fibrillation with box isolation of fibrotic areas: lessons on fibrosis distribution and extent, clinical characteristics, and their impact on long-term outcome. J. Cardiovasc. Electrophysiol. 28, 971-983. doi: 10.1111/jce.13278

Schuessler, R. B., Grayson, T. M., Bromberg, B. I., Cox, J. L., and Boineau, J. P. (1992). Cholinergically mediated tachyarrhythmias induced by a single extrastimulus in the isolated canine right atrium. Circ. Res. 71, 1254-1267. doi: 10.1161/01.RES.71.5.1254

Seitz, J., Bars, C., Theodore, G., Beurtheret, S., Lellouche, N., Bremondy, M., et al. (2017). AF ablation guided by spatiotemporal electrogram dispersion without pulmonary vein isolation: a wholly patient-tailored approach. J. Am. Coll. Cardiol. 69, 303-321. doi: 10.1016/j.jacc.2016.10.065

Seitz, J., Horvilleur, J., Lacotte, J., Mouhoub, Y., Salerno, F., Moynagh, A., et al. (2013). Automated detection of complex fractionated atrial electrograms in substrate-based atrial fibrillation ablation: better discrimination with a new setting of CARTO(R) algorithm. J. Atr. Fibrillation. 6:673. doi: 10.4022/jafib.673

Shah, A. J., Hocini, M., Xhaet, O., Pascale, P., Roten, L., Wilton, S. B., et al. (2013). Validation of novel 3-dimensional electrocardiographic mapping of atrial tachycardias by invasive mapping and ablation: a multicenter study. $J$. Am. Coll. Cardiol. 62, 889-897. doi: 10.1016/j.jacc.2013.03.082

Shah, D., Haissaguerre, M., Jais, P., and Hocini, M. (2003). Nonpulmonary vein foci: do they exist? Pacing Clin. Electrophysiol. 26, 1631-1635. doi: 10.1046/j.1460-9592.2003.t01-1-00243.x

Shen, M. J., Shinohara, T., Park, H. W., Frick, K., Ice, D. S., Choi, E. K., et al. (2011). Continuous low-level vagus nerve stimulation reduces stellate ganglion nerve activity and paroxysmal atrial tachyarrhythmias in ambulatory canines. Circulation 123, 2204-2212. doi: 10.1161/CIRCULATIONAHA.111. 018028

Shi, Y., Li, D., Tardif, J. C., and Nattel, S. (2002). Enalapril effects on atrial remodeling and atrial fibrillation in experimental congestive heart failure. Cardiovasc. Res. 54, 456-461. doi: 10.1016/S0008-6363(02)00243-2

Shinagawa, K., Shi, Y. F., Tardif, J. C., Leung, T. K., and Nattel, S. (2002). Dynamic nature of atrial fibrillation substrate during development and reversal of heart failure in dogs. Circulation 105, 2672-2678. doi: 10.1161/01.CIR.0000016826.62813.F5

Silver, M. A., Pick, R., Brilla, C. G., Jalil, J. E., Janicki, J. S., and Weber, K. T. (1990). Reactive and reparative fibrillar collagen remodelling in the hypertrophied rat left ventricle: two experimental models of myocardial fibrosis. Cardiovasc. Res. 24, 741-747. doi: 10.1093/cvr/24.9.741

Sinner, M. F., Tucker, N. R., Lunetta, K. L., Ozaki, K., Smith, J. G., Trompet, S., et al. (2014). Integrating genetic, transcriptional, and functional analyses to identify 5 novel genes for atrial fibrillation. Circulation 130, 1225-1235. doi: 10.1161/CIRCULATIONAHA.114.009892

Spach, M. S., and Dolber, P. C. (1986). Relating extracellular potentials and their derivatives to anisotropic propagation at a microscopic level in human cardiac muscle. Evidence for electrical uncoupling of side-to-side fiber connections with increasing age. Circ. Res. 58, 356-371. doi: 10.1161/01.RES.58.3.356

Spach, M. S., Dolber, P. C., and Heidlage, J. F. (1988). Influence of the passive anisotropic properties on directional differences in propagation following modification of the sodium conductance in human atrial muscle. A model of reentry based on anisotropic discontinuous propagation. Circ. Res. 62, 811-832. doi: 10.1161/01.RES.62.4.811

Starobin, J. M., Zilberter, Y. I., Rusnak, E. M., and Starmer, C. F. (1996). Wavelet formation in excitable cardiac tissue: the role of wavefront-obstacle interactions in initiating high-frequency fibrillatory-like arrhythmias. Biophys. J. 70, 581-594. doi: 10.1016/S0006-3495(96)79624-8

Stinnett-Donnelly, J. M., Thompson, N., Habel, N., Petrov-Kondratov, V., Correa De Sa, D. D., Bates, J. H., et al. (2012). Effects of electrode size and spacing on the resolution of intracardiac electrograms. Coron. Artery Dis. 23, 126-132. doi: 10.1097/MCA.0b013e3283507a9b

Straube, F., Dorwarth, U., Ammar-Busch, S., Peter, T., Noelker, G., Massa, T., et al. (2016). First-line catheter ablation of paroxysmal atrial fibrillation: outcome of radiofrequency vs. cryoballoon pulmonary vein isolation. Europace 18, 368-375. doi: 10.1093/europace/euv271

Sun, H., Gaspo, R., Leblanc, N., and Nattel, S. (1998). Cellular mechanisms of atrial contractile dysfunction caused by sustained atrial tachycardia. Circulation 98 , 719-727. doi: 10.1161/01.CIR.98.7.719

Tahir, K., Kiser, A., Caranasos, T., Mounsey, J. P., and Gehi, A. (2018). Hybrid epicardial-endocardial approach to atrial fibrillation ablation. Curr. Treat. Options Cardiovasc. Med. 20:25. doi: 10.1007/s11936-018-0613-3

Takahara, A., Sugimoto, T., Kitamura, T., Takeda, K., Tsuneoka, Y., Namekata, I., et al. (2011). Electrophysiological and pharmacological characteristics of triggered activity elicited in guinea-pig pulmonary vein myocardium. J. Pharmacol. Sci. 115, 176-181. doi: 10.1254/jphs.10232FP

Takarada, K., Overeinder, I., De Asmundis, C., Stroker, E., Mugnai, G., De Regibus, V., et al. (2017). Long-term outcome after second-generation cryoballoon ablation for paroxysmal atrial fibrillation - a 3-years follow-up. J. Interv. Card. Electrophysiol. 49, 93-100. doi: 10.1007/s10840-017-0237-7

Takigawa, M., Kuwahara, T., Takahashi, A., Okubo, K., Takahashi, Y., Nakashima, E., et al. (2015a). Simultaneous isolation of superior and inferior pulmonary veins on both the left and right sides could yield better outcomes in patients with paroxysmal atrial fibrillation. Europace 17, 732-740. doi: 10.1093 /europace/euu372

Takigawa, M., Takahashi, A., Kuwahara, T., Okubo, K., Takahashi, Y., Nakashima, E., et al. (2015b). Impact of non-pulmonary vein foci on the outcome of the second session of catheter ablation for paroxysmal atrial fibrillation. $J$. Cardiovasc. Electrophysiol. 26, 739-746. doi: 10.1111/jce.12681

Takigawa, M., Takahashi, A., Kuwahara, T., Okubo, K., Takahashi, Y., Watari, Y., et al. (2017). Long-term outcome after catheter ablation of paroxysmal atrial fibrillation: impact of different atrial fibrillation foci. Int. J. Cardiol. 227, 407-412. doi: 10.1016/j.ijcard.2016.11.028

TIlz, R. R., Heeger, C. H., Wick, A., Saguner, A. M., Metzner, A., Rillig, A., et al. (2018). Ten-year clinical outcome after circumferential pulmonary vein isolation utilizing the hamburg approach in patients with symptomatic drug-refractory paroxysmal atrial fibrillation. Circ. Arrhythm. Electrophysiol. 11:e005250. doi: 10.1161/CIRCEP.117.005250

Tusscher, K. H. W. J. T., and Panfilov, A. V. (2005). Wave propagation in excitable media with randomly distributed obstacles. Multisc. Model. Simulat. 3, 265-282. doi: 10.1137/030602654

Umapathy, K., Nair, K., Masse, S., Krishnan, S., Rogers, J., Nash, M. P., et al. (2010). Phase mapping of cardiac fibrillation. Circ. Arrhythm. Electrophysiol. 3, 105-114. doi: 10.1161/CIRCEP.110.853804

Vaquero, M., Calvo, D., and Jalife, J. (2008). Cardiac fibrillation: from ion channels to rotors in the human heart. Heart Rhythm 5, 872-879. doi: 10.1016/j.hrthm.2008.02.034 
Venteclef, N., Guglielmi, V., Balse, E., Gaborit, B., Cotillard, A., Atassi, F., et al. (2015). Human epicardial adipose tissue induces fibrosis of the atrial myocardium through the secretion of adipo-fibrokines. Eur Heart J. 36, 795-805a. doi: 10.1093/eurheartj/eht099

Verheule, S., Tuyls, E., Gharaviri, A., Hulsmans, S., Van Hunnik, A., Kuiper, M., et al. (2013). Loss of continuity in the thin epicardial layer because of endomysial fibrosis increases the complexity of atrial fibrillatory conduction. Circ. Arrhythm. Electrophysiol. 6, 202-211. doi: 10.1161/CIRCEP.112.975144

Verma, A., Jiang, C. Y., Betts, T. R., Chen, J., Deisenhofer, I., Mantovan, R., et al. (2015). Approaches to catheter ablation for persistent atrial fibrillation. N. Engl. J. Med. 372, 1812-1822. doi: 10.1056/NEJMoa1408288

Verma, A., Novak, P., Macle, L., Whaley, B., Beardsall, M., Wulffhart, Z., et al. (2008). A prospective, multicenter evaluation of ablating complex fractionated electrograms (CFEs) during atrial fibrillation (AF) identified by an automated mapping algorithm: acute effects on AF and efficacy as an adjuvant strategy. Heart Rhythm 5, 198-205. doi: 10.1016/j.hrthm.2007.09.027

Verma, A., Sanders, P., Champagne, J., Macle, L., Nair, G. M., Calkins, H., et al. (2014). Selective complex fractionated atrial electrograms targeting for atrial fibrillation study (SELECT AF): a multicenter, randomized trial. Circ. Arrhythm. Electrophysiol. 7, 55-62. doi: 10.1161/CIRCEP.113.000890

Vigmond, E., Pashaei, A., Amraoui, S., Cochet, H., and Hassaguerre, M. (2016). Percolation as a mechanism to explain atrial fractionated electrograms and reentry in a fibrosis model based on imaging data. Heart Rhythm 13, 1536-1543. doi: 10.1016/j.hrthm.2016.03.019

Vijayakumar, R., Vasireddi, S. K., Cuculich, P. S., Faddis, M. N., and Rudy, Y. (2016). Methodology considerations in phase mapping of human cardiac arrhythmias. Circ. Arrhythm. Electrophysiol. 9:e004409. doi: 10.1161/CIRCEP.116.004409

Viskin, S., Golovner, M., Malov, N., Fish, R., Alroy, I., Vila, Y., et al. (1999). Circadian variation of symptomatic paroxysmal atrial fibrillation. Data from almost 10000 episodes. Eur Heart J. 20, 1429-1434. doi: 10.1053/euhj.1999.1632

Vlachos, K., Letsas, K. P., Korantzopoulos, P., Liu, T., Georgopoulos, S., Bakalakos, A., et al. (2016). Prediction of atrial fibrillation development and progression: current perspectives. World J. Cardiol. 8, 267-276. doi: 10.4330/wjc.v8.i3.267

Vogler, J., Willems, S., Sultan, A., Schreiber, D., Luker, J., Servatius, H., et al. (2015). Pulmonary vein isolation versus defragmentation: the CHASE-AF clinical trial. J. Am. Coll. Cardiol. 66, 2743-2752. doi: 10.1016/j.jacc.2015.09.088

Vogt, J., Heintze, J., Gutleben, K. J., Muntean, B., Horstkotte, D., and Nolker, G. (2013). Long-term outcomes after cryoballoon pulmonary vein isolation: results from a prospective study in 605 patients. J. Am. Coll. Cardiol. 61, 1707-1712. doi: 10.1016/j.jacc.2012.09.033

Voskoboinik, A., Moskovitch, J. T., Harel, N., Sanders, P., Kistler, P. M., and Kalman, J. M. (2017). Revisiting pulmonary vein isolation alone for persistent atrial fibrillation: a systematic review and meta-analysis. Heart Rhythm. 14, 661-667. doi: 10.1016/j.hrthm.2017.01.003

Wakili, R., Voigt, N., Kaab, S., Dobrev, D., and Nattel, S. (2011). Recent advances in the molecular pathophysiology of atrial fibrillation. J. Clin. Invest. 121, 2955-2968. doi: 10.1172/JCI46315

Wang, Y., Cuculich, P. S., Zhang, J., Desouza, K. A., Vijayakumar, R., Chen, J., et al. (2011). Noninvasive electroanatomic mapping of human ventricular arrhythmias with electrocardiographic imaging. Sci. Transl. Med. 3:98ra84. doi: 10.1126/scitranslmed.3002152

Weimar, T., Schena, S., Bailey, M. S., Maniar, H. S., Schuessler, R. B., Cox, J. L., et al. (2012). The cox-maze procedure for lone atrial fibrillation: a single-center experience over 2 decades. Circ. Arrhythm. Electrophysiol. 5, 8-14. doi: 10.1161/CIRCEP.111.963819

Wijffels, M. C., Kirchhof, C. J., Dorland, R., and Allessie, M. A. (1995). Atrial fibrillation begets atrial fibrillation. A study in awake chronically instrumented goats. Circulation 92, 1954-1968. doi: 10.1161/01.CIR.92. 7.1954

Winfree, A. T. (1973). Scroll-shaped waves of chemical activity in three dimensions. Science 181, 937-939. doi: 10.1126/science.181.4103.937

Wu, T. J., Liang, K. W., and Ting, C. T. (2001). Relation between the rapid focal activation in the pulmonary vein and the maintenance of paroxysmal atrial fibrillation. Pacing Clin. Electrophysiol. 24, 902-905. doi: 10.1046/j.1460-9592.2001.00902.x

Xu, J., Luc, J. G. Y., and Phan, K. (2016). Atrial fibrillation: review of current treatment strategies. J. Thorac. Dis. 8, E886-E900. doi: 10.21037/jtd.2016.09.13

Yamada, T., Murakami, Y., Okada, T., and Murohara, T. (2006). Focal atrial fibrillation associated with multiple breakout sites at the crista terminalis. Pacing Clin. Electrophysiol. 29, 207-210. doi: 10.1111/j.1540-8159.2006.00320.x

Yamaguchi, T., Tsuchiya, T., Miyamoto, K., Nagamoto, Y., and Takahashi, N. (2010). Characterization of non-pulmonary vein foci with an EnSite array in patients with paroxysmal atrial fibrillation. Europace 12, 1698-1706. doi: 10.1093/europace/euq326

Yamaguchi, T., Tsuchiya, T., Nakahara, S., Fukui, A., Nagamoto, Y., Murotani, K., et al. (2016). Efficacy of left atrial voltage-based catheter ablation of persistent atrial fibrillation. J. Cardiovasc. Electrophysiol. 27, 1055-1063. doi: 10.1111 /jce.13019

Yang, B., Jiang, C., Lin, Y., Yang, G., Chu, H., Cai, H., et al. (2017). STABLESR (electrophysiological substrate ablation in the left atrium during sinus rhythm) for the treatment of nonparoxysmal atrial fibrillation: a prospective, multicenter randomized clinical trial. Circ. Arrhythm. Electrophysiol. 10:e005405. doi: 10.1161/CIRCEP.117.005405

Yue, L., Xie, J., and Nattel, S. (2011). Molecular determinants of cardiac fibroblast electrical function and therapeutic implications for atrial fibrillation. Cardiovasc. Res. 89, 744-753. doi: 10.1093/cvr/cvq329

Zhang, J., Desouza, K. A., Cuculich, P. S., Cooper, D. H., Chen, J., and Rudy, Y. (2013). Continuous ECGI mapping of spontaneous VT initiation, continuation, and termination with antitachycardia pacing. Heart Rhythm 10, 1244-1245. doi: 10.1016/j.hrthm.2012.01.001

Zhao, J., Hansen, B. J., Csepe, T. A., Lim, P., Wang, Y., Williams, M., et al. (2015). Integration of high resolution optical mapping and 3D Micro-CT imaging to resolve the structural basis of atrial conduction in the human heart. Circ. Arrhythm. Electrophysiol. 8, 1514-1517. doi: 10.1161/CIRCEP.115.003064

Conflict of Interest Statement: The authors declare that the research was conducted in the absence of any commercial or financial relationships that could be construed as a potential conflict of interest.

Copyright (c) 2018 Cheniti, Vlachos, Pambrun, Hooks, Frontera, Takigawa, Bourier Kitamura, Lam, Martin, Dumas-Pommier, Puyo, Pillois, Duchateau, Klotz, Denis, Derval, Jais, Cochet, Hocini, Haissaguerre and Sacher. This is an open-access article distributed under the terms of the Creative Commons Attribution License (CC BY). The use, distribution or reproduction in other forums is permitted, provided the original author(s) and the copyright owner(s) are credited and that the original publication in this journal is cited, in accordance with accepted academic practice. No use, distribution or reproduction is permitted which does not comply with these terms. 